\title{
Development and Testing of the Berkeley Darfur Stove
}

\author{
Susan Amrose ${ }^{1,5}$, G. Theodore Kisch ${ }^{2}$, Charles Kirubi ${ }^{3}$, Jesse Woo ${ }^{4}$, \\ and Ashok Gadgil ${ }^{3,5}$ \\ ${ }^{1}$ Physics Dept, ${ }^{2}$ College of Letters and Sciences, ${ }^{3}$ Energy and Resources Group, and \\ ${ }^{4}$ Mechanical Engineering, \\ University of California - Berkeley \\ ${ }^{5}$ Indoor Environment Department, Environmental Energy Technologies Division, \\ Lawrence Berkeley National Laboratory
}

Berkeley, CA 94720

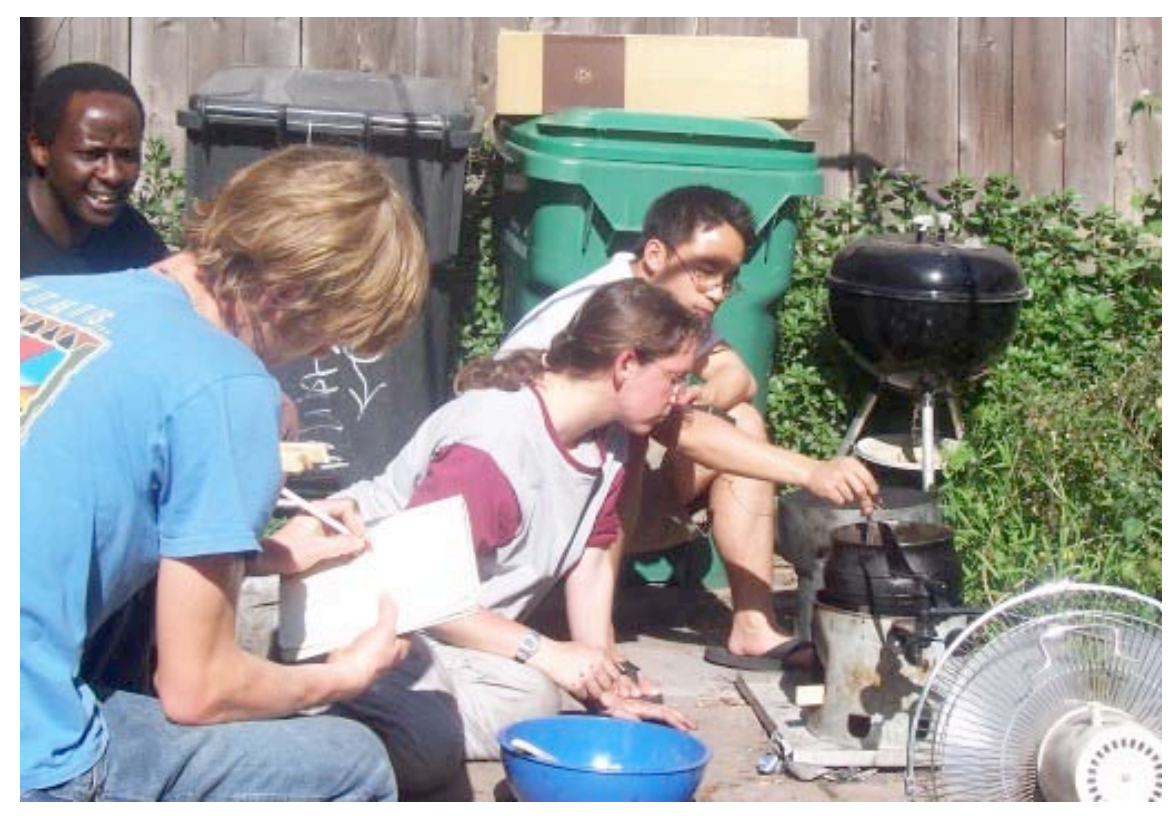

March, 2008

This work was partly supported by the Director, Office of Science, of the U.S. Department of Energy under Contract No. DE-AC02-05CH11231. We are grateful to several individuals for their support (in cash and in kind), through gifts via LBNL or UC Berkeley. We thank the Energy and Resources Group and College of Engineering at UC Berkeley for their support during 2006 to the course ER291 Design for Sustainable Communities, which made this project possible. 


\section{DISCLAIMER}

This document was prepared as an account of work sponsored by the United States Government. While this document is believed to contain correct information, neither the United States Government nor any agency thereof, nor The Regents of the University of California, nor any of their employees, makes any warranty, express or implied, or assumes any legal responsibility for the accuracy, completeness, or usefulness of any information, apparatus, product, or process disclosed, or represents that its use would not infringe privately owned rights. Reference herein to any specific commercial product, process, or service by its trade name, trademark, manufacturer, or otherwise, does not necessarily constitute or imply its endorsement, recommendation, or favoring by the United States Government or any agency thereof, or The Regents of the University of California. The views and opinions of authors expressed herein do not necessarily state or reflect those of the United States Government or any agency thereof or The Regents of the University of California. 


\section{Executive Summary}

Darfur, one of the poorest regions in Sudan, has been in the midst of a complicated and bloody conflict since 2003 that has resulted in the displacement of 2.2 million citizens. The displaced, known as Internally Displaced Persons (IDPs), are crowded into refugee camps scattered across the region with low fuelwood productivity and no alternative means of fuel. Unsustainable harvesting has led to increasing zones of total denudation around the camps, now extending several kilometers in all directions from the camp boundaries. Women who leave the camp to fetch fuelwood are subject to rape and mutilation due to the continuing conflict.

In November of 2005, a team of scientists from LBNL visited Darfur to assess the potential of fuel-efficient stoves ("FES") as a means to mitigate the fuelwood shortage. In addition to conducting a systematic informal survey, the team found that a metal FES, known as the Tara, required 50\% less fuelwood to cook an IDP meal than the inefficient three-stone-fire used by $90 \%$ of the IDPs. The LBNL team emerged from the trip recommending a metal FES based on the Tara, but with two specific design modifications to make it suitable for conditions in Darfur. These included improving the mechanical stability of the stove during vigorous stirring, and maintaining or improving performance during a breeze.

In Spring 2006, an interdisciplinary team of four Berkeley students (3 graduate and 1 senior undergraduate) took on the project of designing, fabricating, and testing the recommended modifications as part of a UC-Berkeley course entitled Design for Sustainable Communities. Under the guidance of Prof. Ashok Gadgil, the students designed several modifications to improve stove performance in windy weather, including a wind-shield around the upper stove body, and the addition of a metal ring to prevent direct air flow through the stove body. Stakes were also added to the stove body to improve stability during vigorous stirring. The students fabricated a prototype for testing, known as the "Berkeley Darfur Stove," or BDS.

Since no existing stove test was relevant to the conditions of Darfur, a new protocol, known as the Darfur Cooking Test (DCT), was developed by the students to compare the fuel efficiency of two stoves. This protocol is specific to the conditions in Darfur, incorporating both windy and non-windy conditions, along with the cooking pots, food preparation methods, and meals employed by IDPs. The complete DCT protocol is presented in Appendices 1 and 2.

The BDS prototype was tested against the original Tara stove using the newly developed DCT along with a simple tipping test (to compare stability). Fuelwood usage by the BDS was found to be consistently less than that of the Tara stove under all tested conditions. Compared to the Tara, the BDS was found to save $56 \%$ (with wind) and $40 \%$ (without wind) of the fuelwood required to cook sauce-like mulah (one of two staple IDP foods) and to save $74 \%$ (with wind) and $8 \%$ (without wind) of the fuelwood required to cook the dough-like assida (the other staple food). Using these numbers, the BDS was found to have a net annual fuelwood savings of $72 \%$ over the three-stone-fire in Darfur. The 
stability of the BDS during stirring was also found to be much better than the Tara, requiring $>117 \mathrm{~N}$ of lateral force to tip compared to just $22 \mathrm{~N}$.

Implications of full adoption of the BDS throughout Darfur include saving 370 million $\mathrm{kg}$ of fuelwood per year, along with a monetary savings of US \$222 per family per year for IDPs who buy fuelwood or a savings of 18 hours of labor effort per week for IDPs who currently collect fuelwood. Annual avoided $\mathrm{CO}_{2}$ emissions would come to 6 million tonnes per year worth $\$ 12$ million annually assuming the lowest market price of $\$ 3$ per tonne ${ }^{1}$ of $\mathrm{CO}_{2}$. Most significantly, the risk of rape and mutilation for those who collect fuelwood would be reduced by three-quarters. Additional expected benefits include substantial reduction in the inhalation of harmful wood-smoke by IDP women and girls, and significant reduction in the risk of fire to the IDP shelters because the BDS fully encloses the open flames.

\footnotetext{
${ }^{1}$ VER market price in Europe, 2007.
} 


\section{Introduction}

Since 2003, a bloody and complicated war in the Darfur region of Sudan has resulted in the displacement of over 2.2 million Sudanese citizens. The displaced, known collectively as Internally Displaced Persons (IDPs) are living in dense camps scattered in arid areas with low fuelwood productivity. Unsustainable harvesting of fuelwood by the IDPs has created ever increasing zones of denudation, that now extend several kilometers in all directions from the camp boundaries. Leaving the safety of the camps to fetch fuelwood from farther and farther away imposes great hardship and risk on the IDP women.

In November of 2005, a group of scientists from LBNL, led by Dr. Ashok Gadgil and with logistical support of CHF International, travelled to Darfur to assess the potential of fuel-efficient stoves (FES) as a means to mitigate the fuelwood shortage. The LBNL team performed systematic informal surveys of IDP households in North and South Darfur to understand the household parameters related to family size, food, fuel, cooking habits, cooking pots, expenditure on fuel, and preferences for spending saved time and money if less fuel could be used. They also tested four pre-existing FES designs side-by-side with the current cooking technology - a three-stone fire. Three of these four FES designs were metal stoves transported to Darfur by the LBNL team, including the Indian-made Tara stove, and the fourth was an improved version of the ITDG mud-and-dung stove that was being locally produced and disseminated. Dr. Gadgil improved the design of the locally produced IDTG stove the best he could -- this improved version was named the Avi stove. The fuel efficiency tests were performed with IDP cooks, using their cookware, cooking methods, and food ingredients. The metal Tara stove was found to use $50 \%$ less fuelwood than the traditional three-stone fire, out performing other designs by large margins. A complete report of the field trip and findings is detailed in Galitsky et al, 2006.

While the Tara stove was clearly the most fuel-efficient of the tested options, the LBNL team made two recommendations for modifications to the Tara design before its dissemination in Darfur: (1) the stove must maintain fuel-efficient performance in the presence of wind and (2) the stove must not tip during the vigorous stirring employed by the IDPs in Darfur. The first recommendation was based on the rapid degradation in fuel efficiency observed during strong breezes. This was noted to probably be the result of using the round-bottomed pots of IDPs rather than the flat-bottomed pots of India for which the Tara stove was designed. The second recommendation stemmed from the experience of IDP cooks who had to use a second person to stabilize the stove while stirring during side-by-side tests. The use of two people to cook is an unreasonable requirement for busy IDP women who frequently cook alone.

In spring 2006, an interdisciplinary team of four UC Berkeley students - Susan Amrose (PhD student in physics), G. Theodore Kisch (Undergraduate senior in Environmental Sciences), Jesse Woo (masters student in Mechanical Engineering) and Charles Kirubi (masters student in the Energy and Resources Group) - took on the task of modifying the Tara stove according to the recommendations of the LBNL team. The modified stove, which came to be known as the Berkeley Darfur Stove, or "BDS", was subsequently 
tested against the Tara using a novel stove test designed specifically for conditions in Darfur. This work was performed as a group project for the spring 2006 course Design for Sustainable Communities (ER291-003) taught by Prof. Ashok Gadgil, who also acted as a mentor and guide to this team.

\subsection{Broad Objectives}

The broad objectives of the student team were to (1) modify the Tara stove according to the two recommendations of the LBNL group to create the Berkeley Darfur Stove (BDS), (2) come up with a reliable and reproducible test to compare the fuelwood use of any two stoves in conditions relevant to Darfur and (3) test the BDS performance to see that both recommendations of the LBNL group were adequately met. A corollary objective was to establish the expected annual fuelwood savings (considering both windy and non-windy conditions) between the BDS and the original three-stone-fire. This number was needed in order to estimate the impact that full-scale dissemination of the stoves could have on the Darfur fuelwood crisis.

\subsection{Specific Objectives}

(1) Design and fabricate the Berkeley Darfur Stove - a modified Tara stove that is stable during vigorous stirring and has minimal convective heat loss during breezy weather when using IDP pots to cook common IDP food.

(2) Establish a reproducible stove test protocol to compare the fuelwood usage of two stoves in conditions relevant to the IDPs of Darfur, including the cooking of common IDP food in IDP pots in both windy and non-windy conditions.

(3) Use the stove test protocol to compare the fuelwood usage of the original Tara stove to the Berkeley Darfur Stove (and by inference to the three-stone fire used in Darfur).

(4) Test the stability of the Berkeley Darfur Stove during vigorous stirring.

\subsection{Outline of the rest of the report}

The rest of the main report details the efforts and results of the student team, including the Tara stove modifications that ultimately lead to the design of the Berkeley Darfur Stove (BDS), the development of the Darfur Cooking Test protocol, and subsequent performance testing of the BDS. The structure of the report is as follows: Section 2 presents the design process of the BDS. Section 3 discusses fabrication of the first BDS prototype. Section 4 presents the development of the Darfur Cooking Test. Section 5 presents the performance testing of the BDS for fuelwood efficiency (using the Darfur Cooking Test) and stability. Finally, Section 6 presents our conclusions. Appendix 1 presents a detailed description of the Darfur Cooking Test protocol and Appendix 2 presents a worksheet intended to guide a user through the protocol. 


\section{Berkeley Darfur Stove Design}

\subsection{Design for Wind}

The Tara stove shows performance degradation in windy conditions. One reason for this is that the Tara stove is designed to work with flat-bottomed cooking pots that fit snugly into the stove body (see Figure 1a) rather than the round-bottomed pots used in Darfur (see Figure 1b). As part of the stove design intended to work with a flat-bottomed pot, three metal pot support brackets are fastened around the top of the Tara stove body (circled in Figure 1a). The lower (L-shaped) part of each bracket (not pictured in Figure 1a) supports the pot while the upper part ensures a small $(\sim 1.5 \mathrm{~cm})$ gap between the pot perimeter and stove wall to allow flue gases to escape while improving heat transfer to the pot. When a large round-bottomed pot is placed on the Tara stove, it sits on top of the pot support brackets (see Figure 1b). This leaves an extended gap of approximately $6 \mathrm{~cm}$ between the pot and the stove body, allowing significant convective heat loss to occur during even a small breeze.

a)

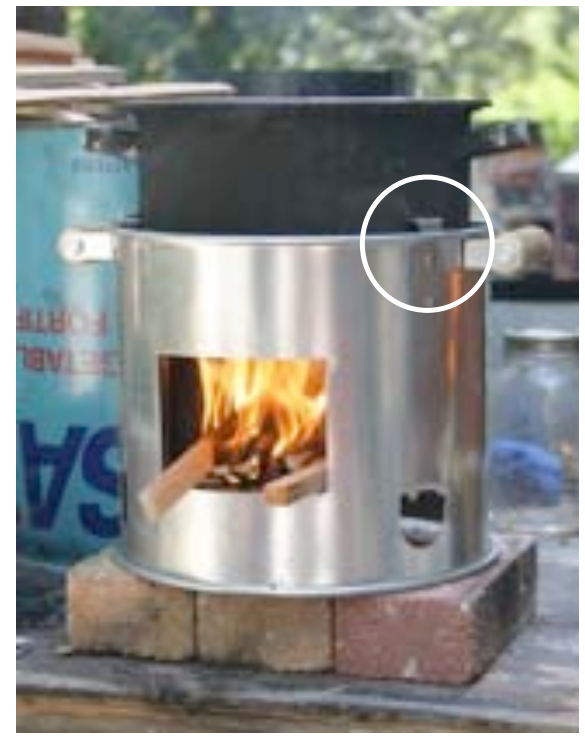

b)

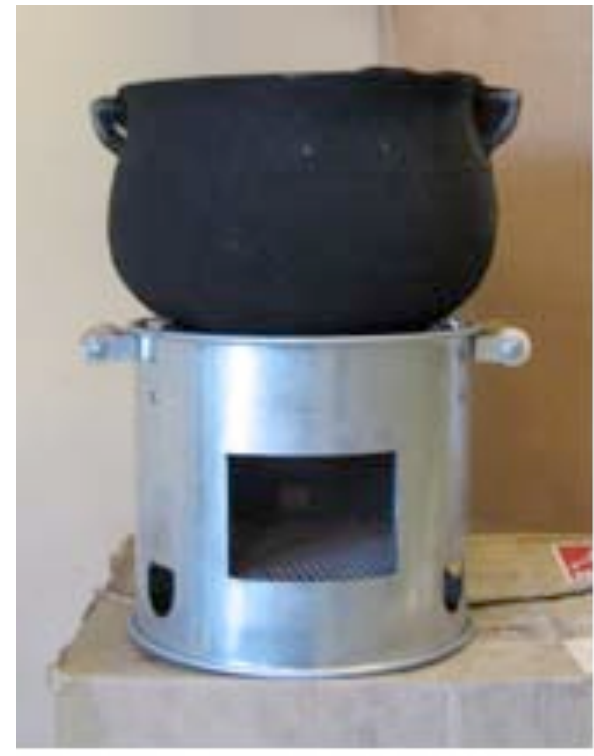

Figure 1: (a) Tara stove holding a flat-bottomed pot. Note the top of one pot support bracket (circled) maintaining a gap between the pot and the stove to allow flue gases to escape. (b) Tara stove holding a round-bottomed pot. Note that the pot now sits on top of the pot support brackets.

Two modifications were made to address convective heat loss via the extended gap. The first was to decrease the horizontal length of the upper pot support brackets by $2 \mathrm{~mm}$ each, thus allowing a round-bottomed pot to sink slightly lower into the stove body (see Figure 2a). The second modification was to erect a wind-shield around the top to the stove body (see Figure 2b) effectively blocking high horizontal winds from the extended gap while still allowing flue gases to escape vertically. One alternative to the wind-shield was to increase the diameter of the entire stove body, allowing the pot to sink in fully. This option was attractive because the stove itself would be made of fewer parts, easing 
manufacture. We chose the addition of the wind-shield instead to ensure good thermal performance for a variety of pot sizes. The most commonly cooked meal in Darfur uses both a small (16-19 cm diameter) and large (23 - $28 \mathrm{~cm}$ diameter) round-bottomed pot (Galitsky et al, 2006). Increasing the diameter of the stove to accommodate the large pot would substantially degrade performance with the small pot due to the now-excessive space between the pot and stove body.

The Tara stove is also vulnerable to performance loss as high-speed air travels unabated through primary air holes cut into the lower stove body. It is essential that some air enter these holes to provide primary air supply to the fire to ensure good combustion; however, a strong wind lead to excess air in the combustion chamber, increasing the air speed up the sides of the stove body as well as the convective heat loss to the pot.

Originally, we planned to replace the primary air holes with vertical cuts in the stove body (see Figure 2c) that could be opened by pressing the sheet metal between the cuts inward, thus allowing air to enter but effectively slowing it down first. This modification was approximated in the first BDS prototype by the more straightforward solution of inserting an inner sheet metal ring just inside the stove body below the grate (see Figure 3 ). This inner ring contains its own primary air supply holes, which are offset from those in the outer stove body, effectively blocking any direct paths for incoming air while still allowing air to enter, thus creating the same effect as the vertical slats. The inner ring worked so well in the prototype that we kept it in later prototypes and abandoned the idea of vertical cuts, which could be more difficult to manufacture and potentially weaken the mechanical strength of the stove body.
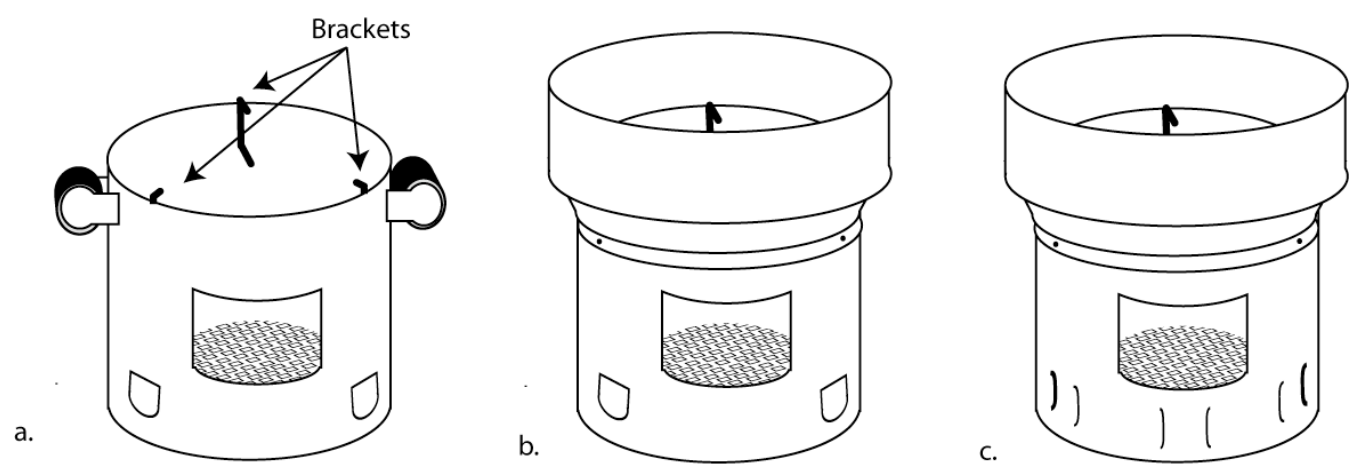

Figure 2: Three modifications to improve performance in wind: (a) reduction in horizontal size of upper pot brackets, (b) wind-shield added to top of stove body, and (c) side-opening slats (vertical cuts with the sheet metal pressed inward) to replace primary air holes along the bottom of the stove body. 


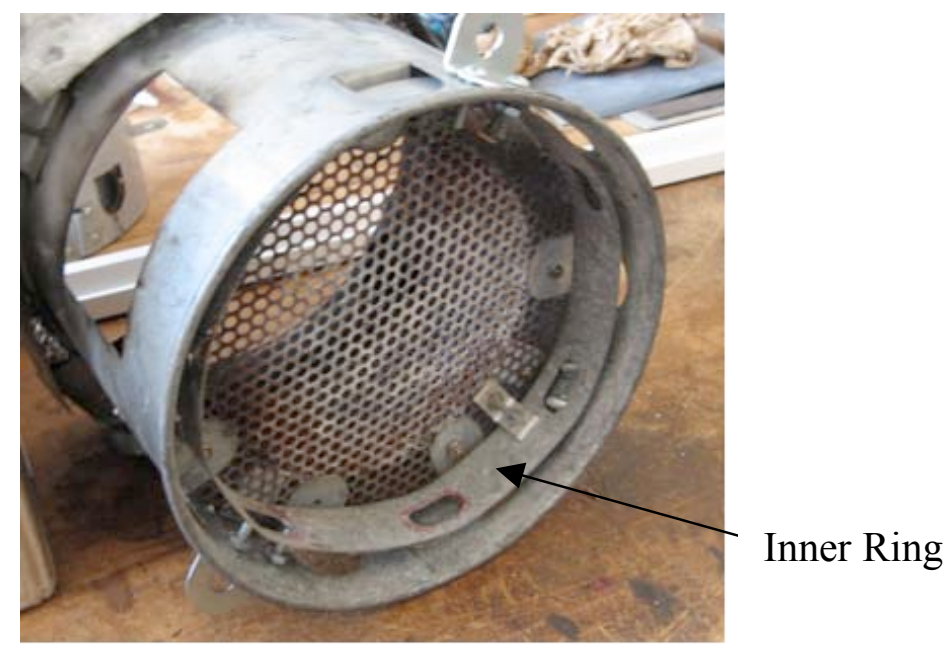

Figure 3: Inner ring to block a direct air path through the primary air holes.

The idea of a hinged door to cover the large opening for fuelwood insertion was considered, but rejected, for several reasons. First, a door prevents the user from being able to continuously monitor and tend the fire, which in turn could encourage overstuffing the stove with fuelwood to keep the fire from going out, resulting in lower fuelwood efficiency overall. Secondly, but equally important, a latched door would require moving parts which tend to wear and break easily from constant use, decreasing the lifetime of the stove while increasing the difficulty of manufacture.

\subsection{Design for Stability}

Our second design goal was to stabilize the stove during the vigorous stirring employed by IDPs while cooking. During the 2005 field trip, the LBNL team observed that the Tara stove was so unstable during strong stirring (in late stages of preparation of assida, a doughy bread-like staple) that IDP women had to team up to stabilize it - with one woman using a stick to stabilize the pot while the other woman continued to stir (Galitsky et al, 2006). The use of two women to cook is unacceptable since IDP women usually cook by themselves.

To solve this problem, we considered a number of options with the requirement that any solution be low-cost, easy to use, and not sacrifice fuelwood efficiency. Initial ideas included the use of rocks (Figure 4a), the use of supporting metal strips in a tripod formation (Figure 4b), hinged pot brackets to grab the pot securely as it is lowered into the stove (Figure 4c), and two large metal rods inserted through the primary air holes and staked to the ground (Figure 4d). The accepted modification was to attach vertical stakes to the sides of the stove (Figure 5). Stakes can be made from recycled materials (perhaps rebar used in concrete) and easily attached using low-cost brackets. They can be pounded into the sandy desert soil using a rock, keeping the stove stable during stirring. Stakes can also be easily pulled out to pick up the stove for ash cleaning and storage. 
a)

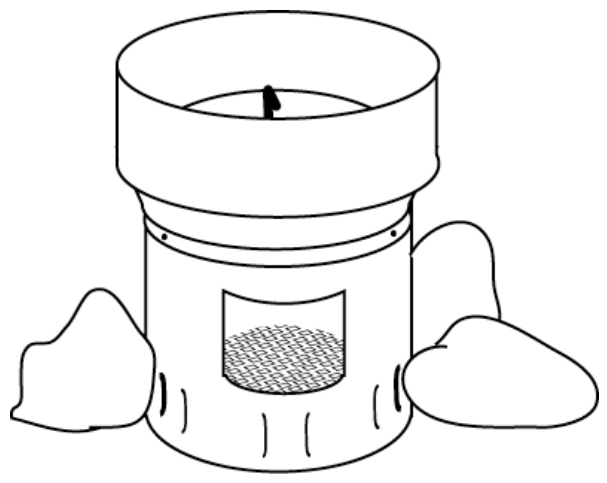

c)

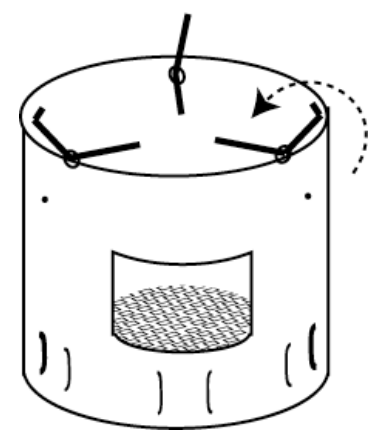

b)

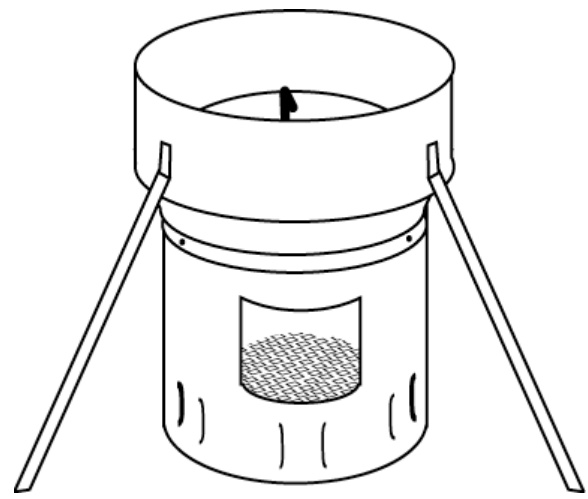

d)

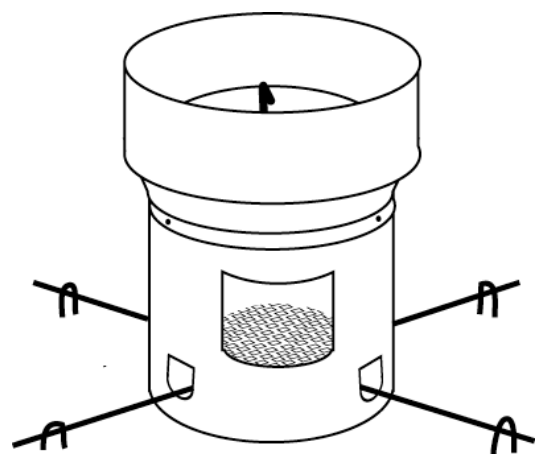

Figure 4: Some of the rejected stability modifications - (a) the use of three large rocks, (b) supporting strips of metal in a tripod formation, (c) rotating pot brackets to secure the pot in place, and (d) long rods placed through the primary air holes and staked to the ground.

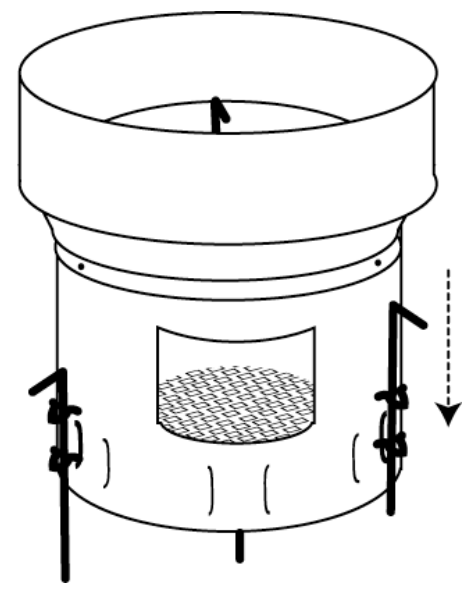

Figure 5: The final stability design accepted for the Berkeley Darfur Stove - three bent stakes are attached by two brackets to the stove body. These stakes can be pounded into the soil to ensure stability during vigorous stirring. 


\section{Fabrication of the Berkeley Darfur Stove Prototype}

The Berkeley Darfur Stove prototype was created from an original Tara stove (as pictured in Figure 1a) in the following manner:

1) The wooden handles were removed for ease of design modifications.

2) The upper pot brackets (see circled region in Figure 1a) were cut down by $2 \mathrm{~mm}$.

3) A thin mild steel sheet metal strip was cut out and rolled into a cylinder $32 \mathrm{~cm}$ in diameter and $12 \mathrm{~cm}$ high to make the wind shield. Three square tabs were cut from the lower half of the cylinder and bent in to attach the shield to the stove body using a screw-nut fastener.

4) The gap between the wind-shield and stove body was filled in with aluminum foil.

5) A $3.8 \mathrm{~cm}$ high sheet metal strip was rolled into cylinder with a diameter of $23 \mathrm{~cm}$ to make the inner ring. Primary air holes were cut into the ring and it was fastened below the grate such that the air holes were exactly out of sync with the primary air holes in the stove body.

6) Three off-the-shelf rod brackets were attached using screw-nut fasteners. Three "L" shaped metal rods $(1.5 \mathrm{ft} / 46 \mathrm{~cm}$ each) were inserted into the brackets.

Photographs of the BDS prototype containing both the small $(\sim 19 \mathrm{~cm}$ diameter $)$ and large $(\sim 23 \mathrm{~cm}$ diameter) pots can be seen in Figure 6.

a)

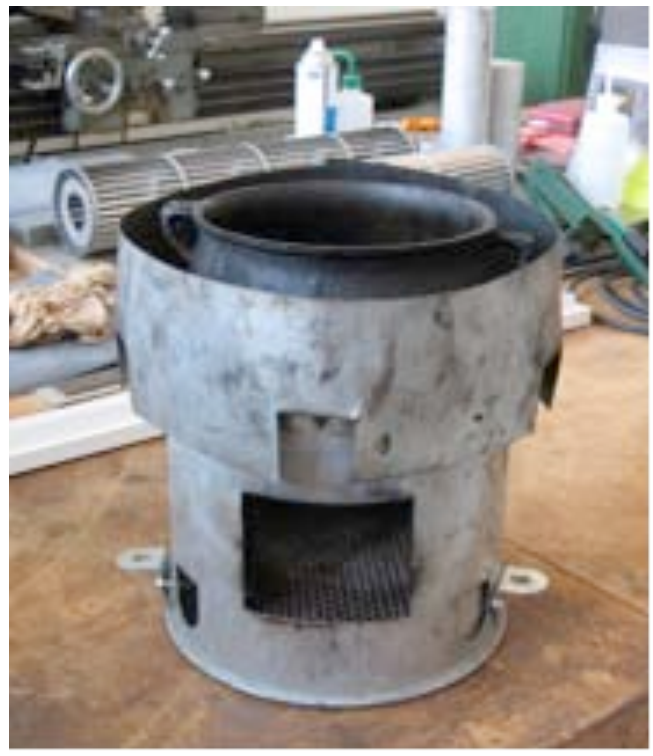

b)

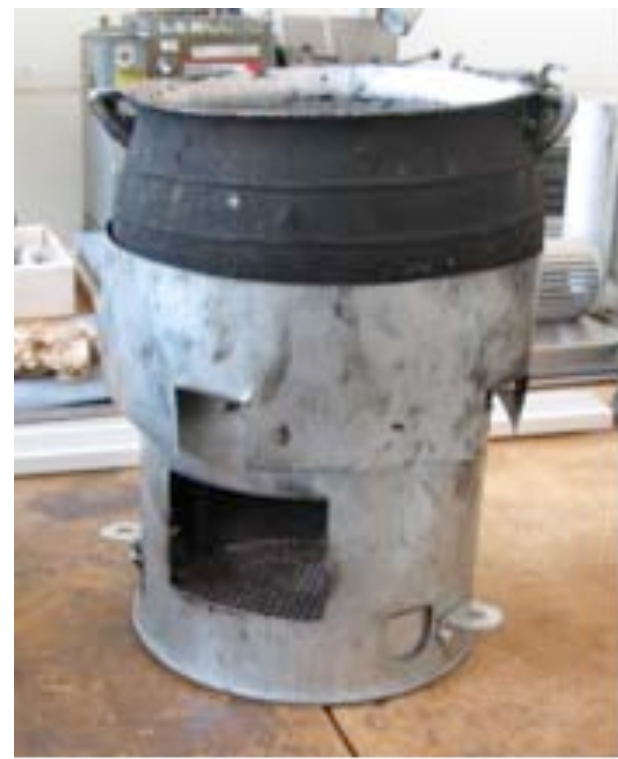

Figure 6: The prototype Berkeley Darfur Stove holding (a) a small mulah pot and (b) a large assida pot. The metal stakes are not shown. 


\section{Development of the Darfur Cooking Test Protocol to Measure Fuelwood Savings}

Several standard protocols exist to compare the fuelwood consumption of cookstoves, including the widely used Water Boiling Test (WBT; Balis et al, 2004). However, no published test, to our knowledge, specifically compares the fuelwood use of stoves in the environment of Darfur, including windy conditions, round-bottomed pots, and thermodynamic properties of common IDP food. To test the Berkeley Darfur Stove (BDS) in these conditions, we developed a new reliable and robust stove test called the Darfur Cooking Test (DCT). While the test was developed to compare and modify the designs for the BDS stove, it is general and can be applied to compare any two stoves designed for use in Darfur.

\subsection{Methodology}

The Water Boiling Test (described above) measures fuelwood consumption using the difference in fuelwood weight before and after boiling and simmering water in a standardized way. We based the DCT on a similar methodology, but redefined the standard heating tasks and relevant environmental conditions to mimic those of Darfur.

To define the relevant conditions for the DCT, we looked at the five principal factors, excluding the stove design, that can influence fuelwood efficiency of a cookstove: (1) the cook's fuel tending habits, (2) the fuel (type and quality), (3) the pot, (4) the food, and (5) the possible presence of wind. This last factor is unusual, but highly relevant to IDP camps in Darfur because of the flimsy shelters that provide negligible protection from outside wind. Each of these conditions had to be set and controlled in order to isolate the effect of stove design in our test. Many factors, both straightforward and subtle, come into play when deciding how much control could or should be exerted on each condition. A more detailed discussion follows.

It is well known that repeated testing reveals an inherent variability in the amount of fuelwood consumed to cook a given meal. An IDP woman cooking the same dinner will find herself using a different amount of fuelwood each night. This is due to cumulative effect of many small factors, including changes in the wood diameter, bark- and moisture- content, changes in the quality of ingredients, and human factors leading to variation in fire tending. To be more specific: previously chopped onions may be drier than freshly chopped onions, and hence require less heat to fry; variations in thermal power due to changes in the fuel-feeding rate can affect stove efficiency; variations in incident wind speed and direction can affect heat loss and thus stove performance; and finally, there is variability in deciding when the meal is considered cooked and the stove is extinguished. If the fuelwood consumed for each meal is measured, then the data for several same-sized meals will show scatter around an average value, and the size of the scatter (measured perhaps by the standard deviation) will reflect the variability found in the entire cooking process. In choosing to set up a more realistic environment for our stove test, we risk incorporating some of this variability into our results as well. 
Some of these factors can be controlled more easily than others. For example, we quickly determined a reproducible way to decide when the onions for the mulah can be considered cooked using the temperature of onions as they are fried (see below). Other factors proved to be much harder (or expensive) to control and reproduce test-to-test, such as steady low-speed wind, fire tending technique, and size distribution (in diameter) of wood pieces. Control of these factors could be obtained at a high cost (both in time and money) by conducting the test in a wind tunnel for accurate steady wind, using machine-made wood pieces of standardized size distribution with a fixed bark-toheartwood ratio and moisture content, and specifying an exact fire-feeding schedule of wood pieces by diameter and time. However, even with these controls, hard-to-obtain data would still be required as inputs regarding the variability of these parameters in the field, such as seasonal variability in the wind speed and the moisture content of wood, variability in the personal choices of fuel-feeding rates, and extent of exposure to wind (i.e., quality of shelter), etc. In the end, the final test protocol tried to reach a balance between an excessively onerous, complicated or expensive test procedure on the one hand, and a quick and easy, but overly simplistic test procedure on the other hand.

In addition to the ease of control, it was also necessary to consider the subtle tradeoffs between a more controlled environment and a more realistic environment. As we have seen, some variability is inherent in cooking process itself. In reducing this variability, we risked sacrificing the very realism we were trying to foster. For example, if we chose to boil water instead of fry onions to mimic a common IDP sauce, we would have reduced the variability associated with onions (e.g. finely chopped onions may perform differently than coarsely chopped ones), but lost valuable information relevant to fuelwood efficiency in Darfur (since frying onions is a very different thermodynamic task than boiling water). Thus, a balance was always kept between a highly reproducible and simplistic test with low scatter in the results versus a more realistic test with slightly more scatter in the results. The full development of a "worst-case" test, including extreme conditions that would lead to the lowest possible efficiency, would require a deep understanding of how each element contributes to the total fuelwood use, knowledge that we don't currently have and that is beyond the scope of this work. A "worst-case" test would also fail to provide an estimate of the expected fuelwood savings under average conditions.

We have attempted to carefully select realistic conditions that are highly relevant to the fuelwood efficiency of a stove and not include those that only add to the variability of our results. In addition, the DCT is set up as a comparison test between a test stove and a standard stove, each tested under the same conditions at the same time. This helps to reduce variability in seasonal produce and fuelwood, fire-tending techniques, etc. Even so, the use of realistic conditions has inevitably resulted in a test with more variability than a less-realistic, but more reproducible, test such as the Water Boiling Test. As a result, in order for the DCT to distinguish between stoves with a very similar efficiency, multiple tests are required to precisely determine the average fuelwood usage of each stove. When similar stoves must be compared, such as during quality control tests in which different instances of the same stove model are compared routinely, a more narrowly defined, and easily reproducible version of the test (such as boiling water in the 
round-bottomed pot) might be more appropriate. The DCT is ideal when comparing the fuel efficiency of two distinct stoves (i.e., of different designs) intended for use by IDPs in Darfur.

\subsubsection{Standard Heating Tasks}

The standard heating tasks of the DCT mimic the cooking of staple foods from IDP camps. Galitsky et al (2006) reported that a common IDP meal consists of two dishes. The first is a sauce known as mulah. It is traditionally prepared in a small roundbottomed pot from sautéed onion, garlic, okra, dried meat, (or yogurt in place of meat), dried tomato, rock salt, and chili. This is served over cooked dough, known as assida. The assida is made in a large round-bottomed pot as a dense, glutinous, semi-moist flourand-water preparation, cooked over high heat until the water is completely absorbed and the starches coalesce. Both dishes are made consecutively in the same cooking session and both require different types of heating from the stove. The heat from the stove during mulah preparation primarily goes to the task of frying (or sautéing) onions in oil, which involves driving out most of the water from within the onions until the onions begin to brown. During assida preparation, stove heat is used to bring the water to a boil and then simmer the water-dough mixture until all the water is absorbed. Since the fuelwood demands from each dish are significant, both the mulah and assida preparation were included in the DCT. To save time during the test, we focused on the main thermodynamic properties of each dish, defining a proxy-mulah and proxy-assida that would require the same amount of fuelwood to cook.

For the proxy-mulah in our test, we used only oil and onions in our recipe, since much of the heat supplied to the pot goes into the latent heat of evaporation of water as it is driven out of the onions. According to field observations of Gadgil and Galitsky ${ }^{2}$, mulah contains about $400 \mathrm{~mL}$ of oil and $3.5 \mathrm{cups} / 840 \mathrm{~mL}(\sim 470 \mathrm{~g})$ of chopped onions. We chose to use half of this amount in our proxy-mulah $(200 \mathrm{~mL}$ oil and $1.75 \mathrm{cups} / 420 \mathrm{~mL}(\sim 235 \mathrm{~g})$ of chopped onions) in order to decrease the total time and materials for each test. While this will decrease the total fuelwood use in the test, the decrease is expected to be similar for each stove being compared, and thus should not significantly effect the estimation of fuelwood savings, though a more thorough study is recommended (see section 5.4). The ingredients were placed in the small $(\sim 19 \mathrm{~cm}$ diameter) round-bottom cast aluminum pot (obtained from Darfur) and constantly stirred at a rate of approximately 1 bowl diameter per second (following mulah preparation as observed by Gadgil and Galitsky ${ }^{3}$ ). A thermocouple was taped to the tip of the wooden spoon used for stirring. The tip of the thermocouple was secured approximately $1 \mathrm{~cm}$ from the bottom of the spoon and bent slightly outward to ensure no interference from the thermal mass of the spoon. At this distance, the thermocouple was always submerged in the onion/oil mixture. In the field, mulah is complete when the onions begin to brown, denoting the time when the water has completely boiled away from the chopped onions. In the DCT, we stopped the mulah heating task when the thermocouple reached $120^{\circ} \mathrm{C}$, a reproducible proxy for same

\footnotetext{
${ }^{2}$ Ashok Gadgil, from field notes via private communication.

${ }^{3}$ Ibid.
} 
thermodynamic point. This number was established through a brief scientific study of onion frying, described in section 4.1 .5 below.

In Darfur, the preparation of assida begins with boiling $\sim 2500 \mathrm{~mL}$ of water in the large (23-28 cm diameter) round-bottomed cast-aluminum pot, followed by adding flour and simmering the mixture in the open pot with constant stirring, until all of the water has been absorbed by the dough (about 15 minutes). The heat required to increase the temperature of the flour is minimal in comparison to boiling and then maintaining the temperature of the water for 15 minutes, therefore the flour has been omitted for the DCT. For proxy-assida, we recommend using the same amount of water as the IDPs use in assida, $2500 \mathrm{~mL}$.

We received contradictory information regarding the use of a lid as the water is brought to a boil for making assida. In 2005, Galitsky et al (2006) observed that no lid was used during side-by-side tests by IDP women cooks, who were told to bring everything they would normally use to cook a meal. Based on this information, the pot was left uncovered and stirred for the entire duration of all assida tests described here. However, during a second trip to Darfur in July 2006, we (Gadgil and Amrose) were told by NGO workers who regularly visit IDP camps that the IDP women traditionally do cover the pot as water is brought to a boil during assida preparation (there is no dispute that the mixture is stirred during the simmer phase). More research into the cooking habits of IDP women is needed to determine lid use as the water is brought to a boil for assida tests.

\subsubsection{Adding the wind}

As the windy season was reported to be quite severe with little adequate shelter for cooking (Galitsky et al, 2006), we simulated the wind using a table fan pointed directly at the stove $e^{5}$ such that the air speed near the top of the stove measured 4-6 mph $(2-3 \mathrm{~m} / \mathrm{s})$ on a cup anemometer. This number takes into account the ability to find some shelter from the wind. Our test also included a component in still air to get an idea of the fuelwood savings expected over one full year (of which only $\sim 6$ months is windy).

During DCT trial tests, the wind condition was the hardest to reliably reproduce. Ambient wind was always present and the anemometer reading frequently fluctuated outside the range 4-6 $\mathrm{mph}(2-3 \mathrm{~m} / \mathrm{s})$, including some gusts as high as $7 \mathrm{mph}(3 \mathrm{~m} / \mathrm{s})$ and some quiescent lows as low as $1 \mathrm{mph}(0.4 \mathrm{~m} / \mathrm{s})$. To account for this, the team member in charge of stirring also watched the anemometer reading carefully. If gusts more than $5 \mathrm{mph}$ (2 $\mathrm{m} / \mathrm{s}$ ) out of range occurred for a significant duration (more than $1 / 8$ of the total time for the test), the test results were discarded.

\footnotetext{
${ }^{4}$ Ibid

5 The use of the fan simulated a constant wind flow from a single direction, whereas actual wind generally comes in gusts and could be from different directions. Further study is needed to determine the effect of gusty wind versus constant wind. However, since constant wind is the more conservative choice (a gusty wind would likely cause the stove to use less wood), we have used it here to obtain a lower limit on the fuelwood savings.
} 


\subsubsection{Mimicking the remaining conditions}

\section{The Pot}

To adequately represent stove performance in Darfur, pots must be round-bottomed and similar in material and shape to those used by IDPs (see Galitsky et al, 2006 for a survey of pot diameters and shapes). For BDS testing, we were able to procure one large $(23 \mathrm{~cm}$ diameter) and one small (19 cm diameter) "Tungutungus" pot directly from Darfur (Figure 7). Pots should be cooled to ambient temperature with water before each test (if hot from use in a preceding test).

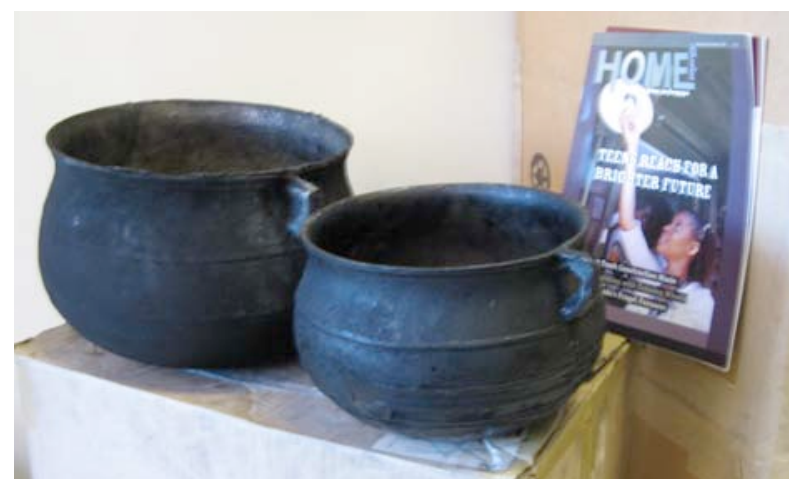

Figure 7: IDP pots from Darfur used in testing. A standard sized magazine (U.S. letter paper size, $8.5 \times 11 \mathrm{inch} / 21.6 \times 27.9 \mathrm{~cm}$ ) is in the background for scale.

\section{The Fuel}

Ideally, the same type of wood used in Darfur (paying attention to hard- versus soft-wood and moisture content) would be used in all tests. However, often this is not feasible. At a minimum, the wood type (hard versus soft) should be kept constant for all tests and the wood cut into small sticks (approximately $20 \mathrm{~cm} \times 3 \mathrm{~cm}$ ) similar in diameter to those used by IDPs (see Galitsky et al, 2006 for more fuelwood details). For BDS testing, a local bundle of soft wood was used (bought at Berkeley Bowl Marketplace in Berkeley, CA).

\section{Cook's Fuel Tending Habits}

The cook's fuel tending habits define the rate at which wood is added to the fire, which amounts to regulating the thermal power of the stove (the $\mathrm{kW}$ of heat output). This is known to have a large effect on stove efficiency since the cook can choose to either keep a large amount of wood burning in the stove (a large fierce fire), or a few pieces of wood (a small frugally-fed fire). The former method, known as "stuffing the firebox," generally produces a higher heat rate (more $\mathrm{kW}$ ) while lowering the thermal efficiency due to the greater loss of excess heat, requiring more fuel to complete the same task. The latter method produces heat at a lower rate (fewer $\mathrm{kW}$ ), but more of the heat is absorbed into the pot, lowering the total fuel requirement. Stuffing the firebox is often used because it decreases the total cooking time and many people are unaware that it uses more fuel (having never tried the frugal method). The LBNL team recommends training IDP women in more efficient fuel tending techniques to further reduce fuelwood usage 
(Galitsky et al, 2006). Therefore, we have used the more efficient fuel tending techniques in the DCT.

Variability in fire-tending techniques is one of the largest sources of uncertainty in the DCT. To increase consistency of results, the DCT splits the jobs of a single IDP cook between two people - the "stirrer" and the "fire-tender," where only the fire-tender has the job of adding fuel to the stove. Some care should be taken to train the fire-tender in consistent fire tending, going through several trial tests in which no hard data is recorded. Each fire-tender should keep track of his or her variation in fuelwood use between identical tests and try to reduce variation as much as possible. In addition, the same person should act as fire-tender for each heating task (recall that the DCT is a comparison test between two stoves, so the same heating task is always performed at least twice). To help fix the fire-tender's habits, we have established the following rules of thumb: 1) feed one piece of wood at a time, 2) feed wood as slowly as possible such that the fire never goes out, and 3) thoughtfully attempt to be as consistent as possible between tests. When testing the BDS, each fire-tender was first trained, repeating at least three sets of identical comparison tests.

\subsubsection{Quantifying the Relative Fuelwood Savings}

Fuelwood usage for a given stove was determined from the difference in fuelwood weight before and after completion of a standard heating task (either mulah or assida). The initial pile of fuelwood, including any kindling required to start the fire, was weighed to the nearest gram using a bench-top electronic scale. When the cooking task was complete, the fire was put out using a small amount of sprinkled water and all of the charred wood remaining in the firebox was collected and weighed. This was combined with the weight of the unused fuelwood and subtracted from the initial weight to get the weight of the fuelwood consumed during the standard heating task (see Appendix 1 and 2 for a detailed breakdown of the calculation). The use of water to douse the fire was estimated to add about 1-2 grams of weight to the charred wood. As the DCT is a comparison test, and the same amount of water was used each time, no correction to the weight was made for dousing water.

The stove was lit using three pieces of phonebook paper (not included in the initial weight) and kindling (included in the initial weight). The pot was not put onto the stove and the wind was not turned on until the kindling had caught fire.

The fuelwood savings, $F S_{A B}$, is a comparative measure describing the percentage of fuelwood saved when one uses Stove B instead of Stove A for a given heating task. It is calculated as:

$$
F S_{A B}=\frac{W_{A}-W_{B}}{W_{A}} * 100
$$

where $\mathrm{W}_{\mathrm{A}}$ is the weight of fuelwood used by Stove $\mathrm{A}$ and $\mathrm{W}_{\mathrm{B}}$ is the weight of fuelwood used by Stove B. 


\subsubsection{Range-top Onion Frying Tests}

In the field, the mulah-cook judges by eye that the onions have begun to brown and removes them from the fire. To establish a more reproducible and reliable indicator to end our mulah heating task, we studied onion frying in a controlled environment to correlate the time at which onions begin to brown with an objectively measurable event.

In order for onions to become translucent and brown, the water in the onion must be mostly boiled off. Initially, heat from the cooking pot raises the temperature of both the onions and the water inside. Once the water starts to boil, some additional heat (known as latent heat) is required to turn the water into steam. During this time, heat is still added to the water but the temperature does not rise. It is only after all of the water is converted into steam that the incoming heat energy can again be used to increase the temperature of the onions, eventually causing them to brown and (if left in the heat) to burn. This behavior is easy to pick out from a graph of temperature versus time. If the heat added to the onion/oil mixture is perfectly uniform, then the temperature initially rises, followed by a clear levelling off as the water is converted from liquid to steam (during boiling), followed by another rise after the water is completely boiled away. The second rise in temperature bends upwards like an elbow on a graph of temperature versus time, hence it is sometimes called the Elbow Point. Having the ability to measure the temperature of the oil/onion mixture during cooking, we set out to (1) determine if we could see the Elbow Point in a mixture that was not uniformly heated, and (2) to characterize that point either by its temperature or time of onset.

Since the water in the onions is not "free liquid" water, but has dissolved material in it, and is bound to the onion at the cellular level, we did not expect to see a single sharp boiling point at $100^{\circ} \mathrm{C}$ as free liquid water would have. Rather we expected the water to boil off over a small range of temperature, and after that range is exceeded, to begin to rise sharply.

Using a thermocouple taped to a wooden spoon, we measured the temperature profile of an onion/oil mixture (200mL oil, $1.75 \mathrm{cups} / 420 \mathrm{~mL}$ chopped onions) heated in a standard American flat-bottomed pot on an electric stove range (Figure 8). Each test started at ambient temperature and was stopped just as the onions began to burn. Two identical tests were performed for repeatability. The initial levelling off near $100^{\circ} \mathrm{C}$ is clear in Figure 8 . There is also a clear difference in the slope immediately after the mixture reaches $100^{\circ} \mathrm{C}$ (from 6-9 $\mathrm{min}$ ) and once the temperature starts to rise dramatically (from 16-21 $\mathrm{min}$ ). However, the change in slope between these two regions is gradual with no obvious sharp Elbow Point. We therefore chose the Elbow Point to be directly in between at about $120^{\circ} \mathrm{C}$. Our observations verified that the onions were indeed starting to turn brown at this point. Therefore, $120^{\circ} \mathrm{C}$ was chosen to be the stopping point for our mulah heating task.

Several similar tests were earlier performed on a gas range. While the temperature profiles had similar shapes to those on the electric range, the total time required to complete the task was found to be erratic and non-reproducible. This was perhaps due to the spatial distribution of power across the burner of a gas range, difficulty in accurately 
reproducing the thermal power of the gas burner from test to test, or inconsistencies in the procedure that were later corrected.

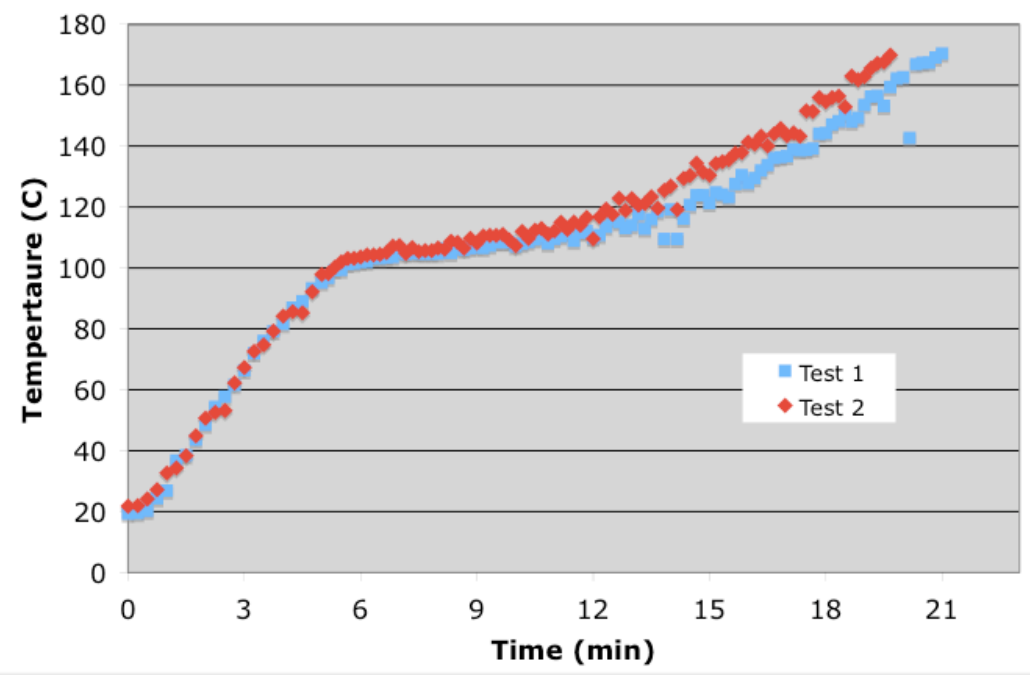

Figure 8: The temperature profile of an onion/oil mixture heated on an electric range. The Elbow Point was observed to be at $120^{\circ} \mathrm{C}$.

\subsection{Components of the Full Testing Protocol}

The goal of the Darfur Cooking Test is to compare the fuelwood use of two stoves under realistic conditions (relevant to fuelwood efficiency) similar to those found in Darfur. In order to incorporate all of the relevant variables, including the wind and no-wind cooking of both mulah and assida for both stoves, the final stove test protocol consists of 8 separate tests. Each test includes lighting the stove and dousing the fire one time. The individual tests are listed in Table 1.

A detailed description of the full Darfur Cooking Test protocol is presented in Appendix 1. A worksheet to be filled out during the DCT including all of the relevant information to measure the fuelwood savings is presented in Appendix 2. 
Table 1: Components of one full Darfur Cooking Test. The two stoves being compared are denoted $A$ and $B$.

\begin{tabular}{|c|c|c|c|}
\hline No. & Stove & Heating Task & Wind Condition \\
\hline $\mathbf{1}$ & A & Mulah & No Wind \\
\hline $\mathbf{2}$ & B & Mulah & No Wind \\
\hline $\mathbf{3}$ & A & Mulah & Wind \\
\hline $\mathbf{4}$ & B & Mulah & Wind \\
\hline $\mathbf{5}$ & A & Assida & No Wind \\
\hline $\mathbf{6}$ & B & Assida & No Wind \\
\hline $\mathbf{7}$ & A & Assida & Wind \\
\hline $\mathbf{8}$ & B & Assida & Wind \\
\hline
\end{tabular}

\section{Testing the Berkeley Darfur Stove}

\subsection{Materials and Methods}

The Berkeley Darfur Stove (BDS) was tested against the Tara stove to determine fuelwood savings and comparative mechanical stability. Each is described in turn.

\subsubsection{Fuelwood savings of the BDS over the Tara}

To measure the fuelwood savings of the BDS compared to the Tara stove, we followed the Darfur Cooking Test protocol as described in Section 4 and Appendix 1. Stove A was always the Tara stove and Stove B was always the BDS. All tests were performed outdoors in Berkeley, CA (either at LBNL or a private residence). Tests were performed outdoors near a structure to shelter the stove on at least two sides in an attempt to isolate it from ambient wind (e.g., see the photo on the front cover of this report). When ambient wind was measured to be $>2 \mathrm{mph}(1 \mathrm{~m} / \mathrm{s})$, tests were not performed. A tarp was used (at least 4 feet/122 $\mathrm{cm}$ above the stove) during rain.

Small deviations from the protocol as written in Appendix 1, such as the use of $2000 \mathrm{~mL}$ of water for the assida test, are noted in sections 4.1.1 - 4.1.3 above. In addition, as the protocol was being refined, some assida tests were performed with a 5-minute simmer phase as opposed to a $15 \mathrm{~min}$ simmer phase. Since the relative fuelwood savings is a comparative measure (and the 5-minute simmer was used for both the BDS and Tara stove), we include the relative fuelwood savings from these tests in our results, but exclude the total fuelwood used from averages.

We recorded the thermocouple reading every 30 seconds for the first few mulah tests without wind to compare the temperature profile during an actual test to the temperature profile of range-top experiments (section 4.2). 
In most cases, the 8 subcomponents of a full stove test (see Table 1) were not performed on the same day. However, like heating tasks (i.e. tests 1-2, 3-4, 5-6, and 7-8) were always performed on the same day and using the same person as a fire-tender.

The four students on the team divided themselves into two person teams in order to increase our total available testing time. Initially, we tried to save further time by testing two stoves (one BDS and one Tara) side by side; one person to stir both pots (one assida and one mulah) and one person to tend both fires. After some time, we realized that this was compromising our test results. It was too hard for the fire-tender to carefully watch and tend both fires at once. In addition the mulah test always went faster, and dousing the fire on one stove inevitably led to neglecting the other for a time. Because the assida test was always the neglected one, the doubling up led to more neglect and more errors in the assida tests than on the mulah tests (where it was not observed to have an impact). In addition, when the fan was providing wind, the neglect of the assida stove was far more disruptive than during the tests without wind. Thus we had to throw away any results for assida tests with wind that were completed during a doubled up test. This accounts for the disproportionate number of mulah tests and assida tests without wind reported in our findings.

Finally, in some cases, the "Total Cooking Time" was not recorded due to miscommunications within the group. Use of Appendix 2 is recommended to prevent similar problems in the future.

\subsubsection{Stability test protocol}

To goal of the stability test was to evaluate the BDS design under conditions of vigorous stirring during assida preparation. As the assida dough solidifies and stirring becomes more difficult, the stirring stick applies a large force outward on the large assida pot near its widest point, causing both the pot and stove to tip. To simulate this, our large roundbottomed pot was filled with $3.4 \mathrm{~kg}$ of water to represent the $3.4 \mathrm{~kg}$ of combined water and flour that usually fills the pot when making assida. A cord was then tied around the widest point on the pot and pulled laterally (Figure 9) to simulate the force of the stirring stick. A hand held scale (essentially a spring balance) capable of measuring up to $12 \mathrm{~kg}$ (117N of force) was used to measure the lateral force just as the stove began to tip. 


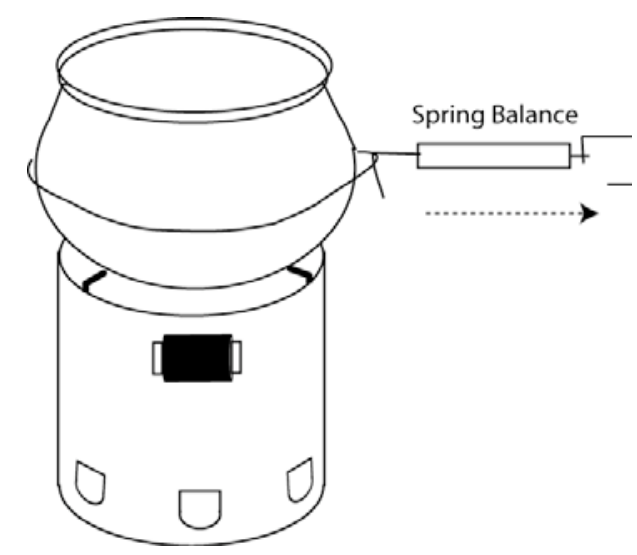

Figure 9: Schematic of the setup for stability testing (showing the Tara stove). The spring balance was pulled laterally until the stove just began to tip.

\subsection{Results}

\subsubsection{Fuelwood Savings}

\subsubsection{Temperature Profile}

The temperature profile of the onion/oil mixture during the mulah test can be seen in Figure 10 . Note that each test was stopped once the temperature reached $120^{\circ} \mathrm{C}$ (per DCT protocol), so the behavior above the Elbow Point is not visible. However, the profiles below the Elbow Point look very similar to those measured on the electric range (Figure 8 ) verifying that the temperature behavior of mulah in a round-bottomed pot on the cookstove is the same as in a flat-bottomed pot on the electric range. In addition, we observed that the onions were nicely brown just as the test was stopped, verifying that $120^{\circ} \mathrm{C}$ is a good indicator of when the onions are fully sautéed.

It is also clear from Figure 10 that mulah reaches both $100^{\circ} \mathrm{C}$ and $120^{\circ} \mathrm{C}$ quicker on the BDS than on the Tara, indicating that the BDS has improved heat transfer to the pot. The BDS saves about 5 minutes over the Tara in the cooking of mulah during non-windy conditions. 


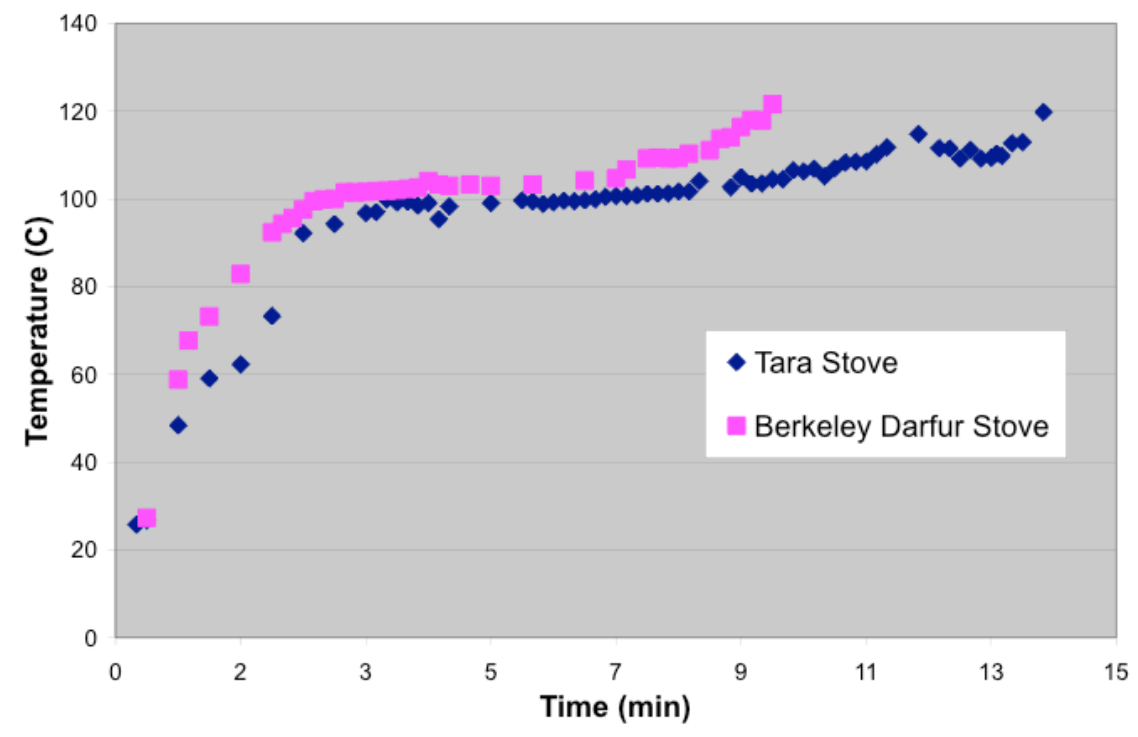

Figure 10: Temperature profile for the onion/oil mixture (mulah) during tests on the Tara stove and BDS (data from test on 3/10/06).

\subsubsection{Mulah tests}

Results of the mulah test for the BDS and Tara stove with and without wind are shown in Table 2 and summarized in Figure 11. The average fuelwood savings of the BDS over the Tara stove is $40 \%$ without wind and $57 \%$ with wind. In the absence of wind, this savings is likely due to cutting back the upper pot support brackets, allowing the small roundbottomed mulah pot to sit closer to the flame. The additional savings in windy conditions is likely due to the wind-shield and lower ring successfully blocking rapid heat loss.

The total cooking time is consistently less for the BDS, by an average of 7 minutes without wind and 8 minutes with wind. However, the large variation in total cooking time (especially with wind) make it difficult to draw conclusions.

Despite efforts to reduce variation between identical tests, relatively large variations exist in the total cooking time and total fuelwood used. This could be due to a number of factors, including variations between fire-tenders (constant across stoves for a single set of tests, but not constant across tests on different dates), variations in the ambient wind, variations in the water content of onions used (also kept constant across stoves for a single test, but not across tests on different dates), and the use of $120^{\circ} \mathrm{C}$ as a hard ending point. The last factor can cause variation in the results if the heat is suddenly reduced (due to temporary loss of flame or a strong gust of ambient wind) just as the temperature is about to reach $120^{\circ} \mathrm{C}$. This did happen in some cases, resulting in a temperature drop of $2-4^{\circ} \mathrm{C}$ after the mixture had reached $119^{\circ} \mathrm{C}$ and was clearly almost done. Insisting that the temperature reach $120^{\circ} \mathrm{C}$ in these cases (when by subjective judgement, the mulah was already done) added 2-3 minutes to the total cooking time and an increase in the amount of fuelwood used. 
Table 2: Mulah test results with and without wind: Tara stove vs. the Berkeley Darfur Stove (BDS).

\begin{tabular}{|c|c|c|c|c|c|c|}
\hline \multirow[b]{2}{*}{ Test Date } & \multicolumn{2}{|c|}{ Tara Stove } & \multicolumn{2}{|c|}{ BDS } & \multicolumn{2}{|c|}{$\begin{array}{c}\text { Savings } \\
\text { (BDS over Tara) }\end{array}$} \\
\hline & $\begin{array}{c}\text { Total } \\
\text { Cooking } \\
\text { Time }^{\alpha} \\
(\min )\end{array}$ & $\begin{array}{c}\text { Fuelwood } \\
\text { Used } \\
\text { (g) }\end{array}$ & $\begin{array}{c}\text { Total } \\
\text { Cooking } \\
\text { Time } \\
\text { (min) }\end{array}$ & $\begin{array}{c}\text { Fuelwood } \\
\text { Used } \\
\text { (g) }\end{array}$ & $\begin{array}{c}\text { Total } \\
\text { Cooking } \\
\text { Time } \\
\text { (min) }\end{array}$ & Fuelwood ${ }^{\gamma}$ \\
\hline \multicolumn{7}{|l|}{ NO WIND } \\
\hline 3/10/06 & 15 & 171 & 11 & 106 & 4 & $38 \%$ \\
\hline $3 / 14 / 06$ & $N A^{b}$ & 302 & $N A$ & 122 & $N A$ & $60 \%$ \\
\hline $4 / 4 / 06$ & 23 & 201 & 17 & 107 & 6 & $47 \%$ \\
\hline $4 / 15 / 06$ & 20 & 215 & 12 & 132 & 8 & $39 \%$ \\
\hline $4 / 18 / 06$ & 31 & 229 & 17 & 156 & 14 & $32 \%$ \\
\hline $4 / 24 / 06$ & 35 & 321 & 32 & 236 & 3 & $26 \%$ \\
\hline Mean & 25 & 240 & 18 & 143 & 7 & $40 \%$ \\
\hline $\begin{array}{l}\text { Standard } \\
\text { Deviation }\end{array}$ & 8 & 59 & 8 & 49 & 4 & $12 \%$ \\
\hline \multicolumn{7}{|c|}{$\overline{W I T H}$ WIND } \\
\hline 4/17/06 & 21 & 354 & 8 & 175 & 13 & $51 \%$ \\
\hline $5 / 1 / 06$ & 14 & 357 & 12 & 152 & 2 & $57 \%$ \\
\hline $5 / 1 / 06$ & $N A$ & 313 & $N A$ & 120 & $N A$ & $62 \%$ \\
\hline Mean & 18 & 341 & 10 & 149 & 8 & $57 \%$ \\
\hline $\begin{array}{l}\text { Standard } \\
\text { Deviation }\end{array}$ & 5 & 25 & 3 & 28 & 8 & $6 \%$ \\
\hline
\end{tabular}

${ }^{\alpha}$ Total Cooking time is the time from initial light-up to reaching $120^{\circ} \mathrm{C}$.

${ }^{\beta}$ Some values for Total Cooking Time are missing due to communication errors during the tests (one of the times did not get recorded).

${ }^{\gamma}$ Fuelwood Savings, $\mathrm{FS}_{\mathrm{AB}}$, is [Wood Used (Tara) - Wood Used (BDS)] x 100/ [Wood Used (Tara)] (see Section 0). 


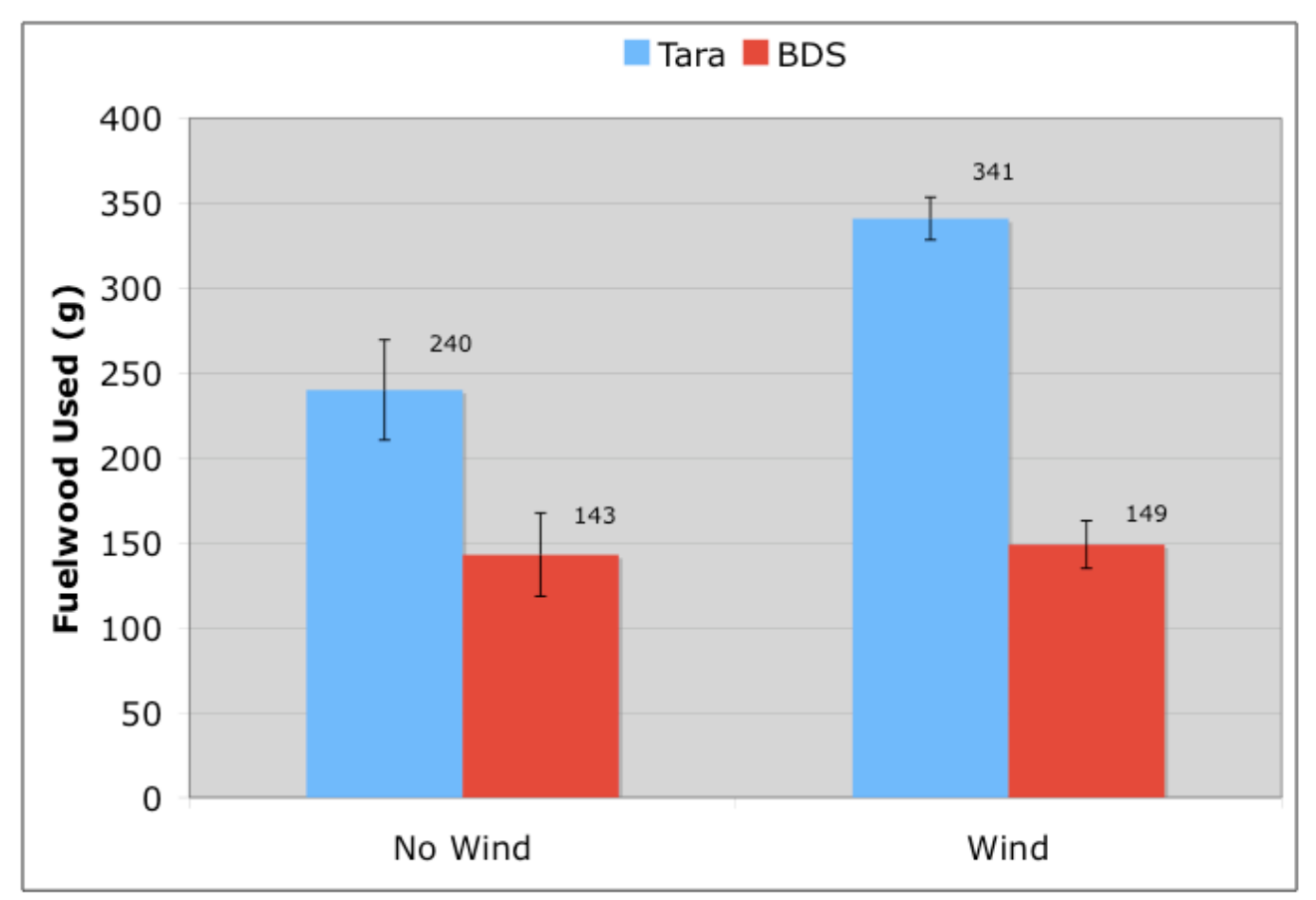

Figure 11: Comparison of the average fuelwood used cooking mulah on the Tara stove and BDS. Error bars indicate the measured variation between tests.

\subsubsection{Assida tests}

Results of the assida test for the BDS and Tara stove with and without wind are shown in Table 3 and Figure 12. The fuelwood savings of the BDS over the Tara is an average of $8 \%$ without wind and $74 \%$ with wind, and consistently positive in all individual tests. Unlike mulah, the advantage without wind is relatively small compared to the huge advantage with wind (Figure 12). The small mulah pot sinks deeper into both the Tara and BDS, meaning that less heat is lost due to wind, and hence less improvement is seen due to the wind collar and inner ring. This indicates that the increase in efficiency for assida is largely caused by the wind collar and inner ring. It also shows the importance of including a wind component in the test of any stove aimed at a windy region like Darfur (note that this advantage would be completely missed without a wind test).

The time-savings between the BDS and Tara stove during assida preparation is similarly much larger with wind than without. Though we have only one test with accurate time information for assida with wind, the measured time-savings ( $>1$ hour) is extremely significant. If an IDP women cooks for half the year in windy conditions, and cooks assida twice a day, this can lead to a time savings of up to 365 hours, or 15 days, per year. However, additional data is needed to more reliabily quantify this savings. 
Table 3: Assida test results without wind and with wind: Tara stove vs. the Berkeley Darfur Stove (BDS).

\begin{tabular}{|c|c|c|c|c|c|c|}
\hline \multirow[b]{2}{*}{ Test Date } & \multicolumn{2}{|c|}{ Tara Stove } & \multicolumn{2}{|c|}{ BDS } & \multicolumn{2}{|c|}{$\begin{array}{c}\text { Savings } \\
\text { (BDS over Tara) }\end{array}$} \\
\hline & $\begin{array}{c}\text { Time to } \\
\text { Boil } \\
\text { (min) } \\
\end{array}$ & $\begin{array}{c}\text { Fuelwood } \\
\text { Used } \\
\text { (g) } \\
\end{array}$ & $\begin{array}{c}\text { Time to } \\
\text { Boil } \\
\text { (min) }\end{array}$ & $\begin{array}{c}\text { Fuelwood } \\
\text { Used } \\
(\mathrm{g})\end{array}$ & $\begin{array}{l}\text { Time to Boil } \\
(\text { min) }\end{array}$ & Fuelwood ${ }^{\gamma}$ \\
\hline \multicolumn{7}{|l|}{ NO WIND } \\
\hline $4 / 15 / 06$ & $27^{\alpha}$ & $521^{\alpha}$ & 27 & 473 & 0 & $9 \%$ \\
\hline $4 / 18 / 06$ & 34 & 545 & 42 & 490 & -8 & $10 \%$ \\
\hline $4 / 26 / 06$ & 21 & 492 & 19 & 464 & 2 & $6 \%$ \\
\hline Mean & 28 & 519 & 29 & 477 & -2 & $8 \%$ \\
\hline $\begin{array}{l}\text { Standard } \\
\text { Deviation }\end{array}$ & 9 & 37 & 12 & 18 & 5 & $2 \%$ \\
\hline \multicolumn{7}{|l|}{ WITH WIND } \\
\hline 4/29/06 & 72 & 2269 & 9 & 460 & 63 & $80 \%$ \\
\hline $5 / 3 / 06$ & $N A^{\beta}$ & 1459 & $N A$ & 454 & $N A$ & $69 \%$ \\
\hline Mean & 72 & 1864 & 9 & 457 & 63 & $74 \%$ \\
\hline $\begin{array}{l}\text { Standard } \\
\text { Deviation }\end{array}$ & $N A$ & 573 & $N A$ & 4 & $N A$ & $8 \%$ \\
\hline
\end{tabular}

${ }^{\alpha} 5$ minutes simmer time compared to 15 minutes - this value not included in average Time to Boil or Fuelwood Used.

${ }^{\beta}$ Some values are missing due to communication errors during the tests (one of the times did not get recorded).

${ }^{\gamma}$ Fuelwood Savings, $F S_{A B}$, is [Wood Used (Tara) - Wood Used (BDS)] x 100/ [Wood Used (Tara)] (see Section 4.1.4). 


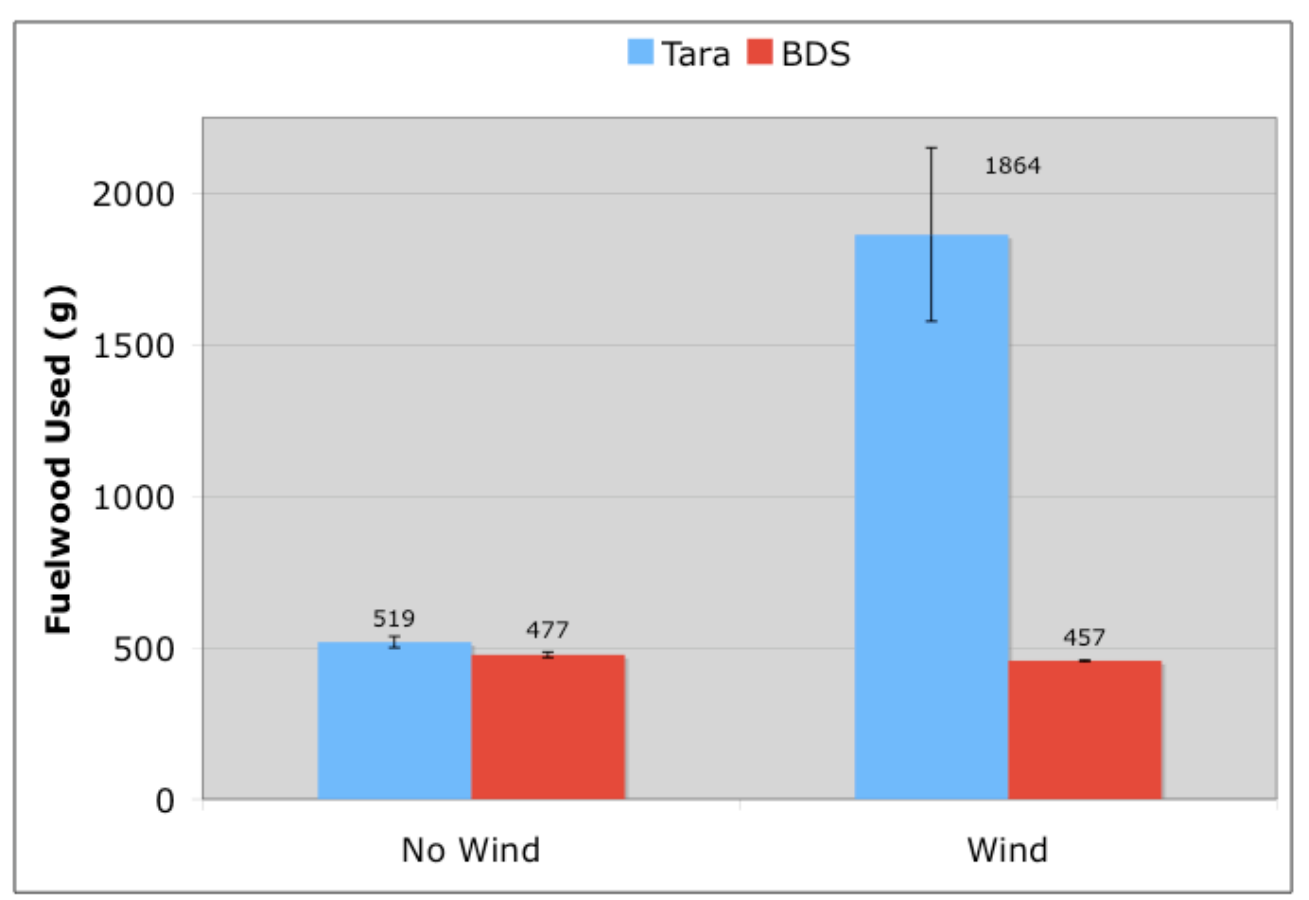

Figure 12: Comparison of the average fuelwood used cooking proxy-assida on the Tara and BDS. Error bars indicate the measured variation between tests.

\subsubsection{Combined fuelwood savings}

The average fuelwood savings of the BDS over the Tara stove measured for mulah and assida tests are summarized in Figure 13.

In 2005, Galitsky et al. measured a fuelwood savings of $50 \%$ for the Tara stove over a three-stone fire in side-by-side field tests with no wind. We can use our test results, which compare the Tara to the BDS, to estimate the fuelwood savings between the BDS and a three-stone fire. To make this calculation, we need to make several assumptions. First, we assume that the IDPs cook under windy conditions for half of the year (as reported to Galitsky and Gadgil via field workers ${ }^{6}$ ). Second, we assume that the Tara stove also saves $50 \%$ fuelwood over the three-stone fire under windy conditions (we have no data for this point). Finally, let us assume that is takes four times as much fuelwood to cook assida as mulah (observed during side-by-side tests in $2005^{7}$ ). The total fuelwood savings of the BDS over a three-stone fire is therefore:

$$
\begin{aligned}
& \text { Savings }=\sum(\text { Tara over three-stone fire savings })(1+\text { BDS over Tara savings }) \\
& \text { (Fraction of year with/without wind) (Fraction of total wood use per dish) }
\end{aligned}
$$

where the sum is over each dish (mulah and assida) and each condition (no wind and wind). Inserting numbers we find:

\footnotetext{
${ }^{6}$ Ashok Gadgil, personal communication, 2006.

${ }^{7}$ Ibid
} 


$$
\begin{aligned}
\text { Savings }= & (0.50)(1+0.40)(1 / 2)(1 / 5)_{\text {mulah }- \text { no wind }} \\
+ & (0.50)(1+0.56)(1 / 2)(1 / 5)_{\text {mula }}-\text { wind } \\
+ & (0.50)(1+0.08)(1 / 2)(4 / 5)_{\text {assida }- \text { no wind }} \\
+ & (0.50)(1+0.74)(1 / 2)(4 / 5)_{\text {assida }- \text { wind }} \\
= & 0.72=72 \%
\end{aligned}
$$

Therefore we estimate the BDS will save $72 \%$ of the fuelwood currently used in a threestone fire over the course of one year.

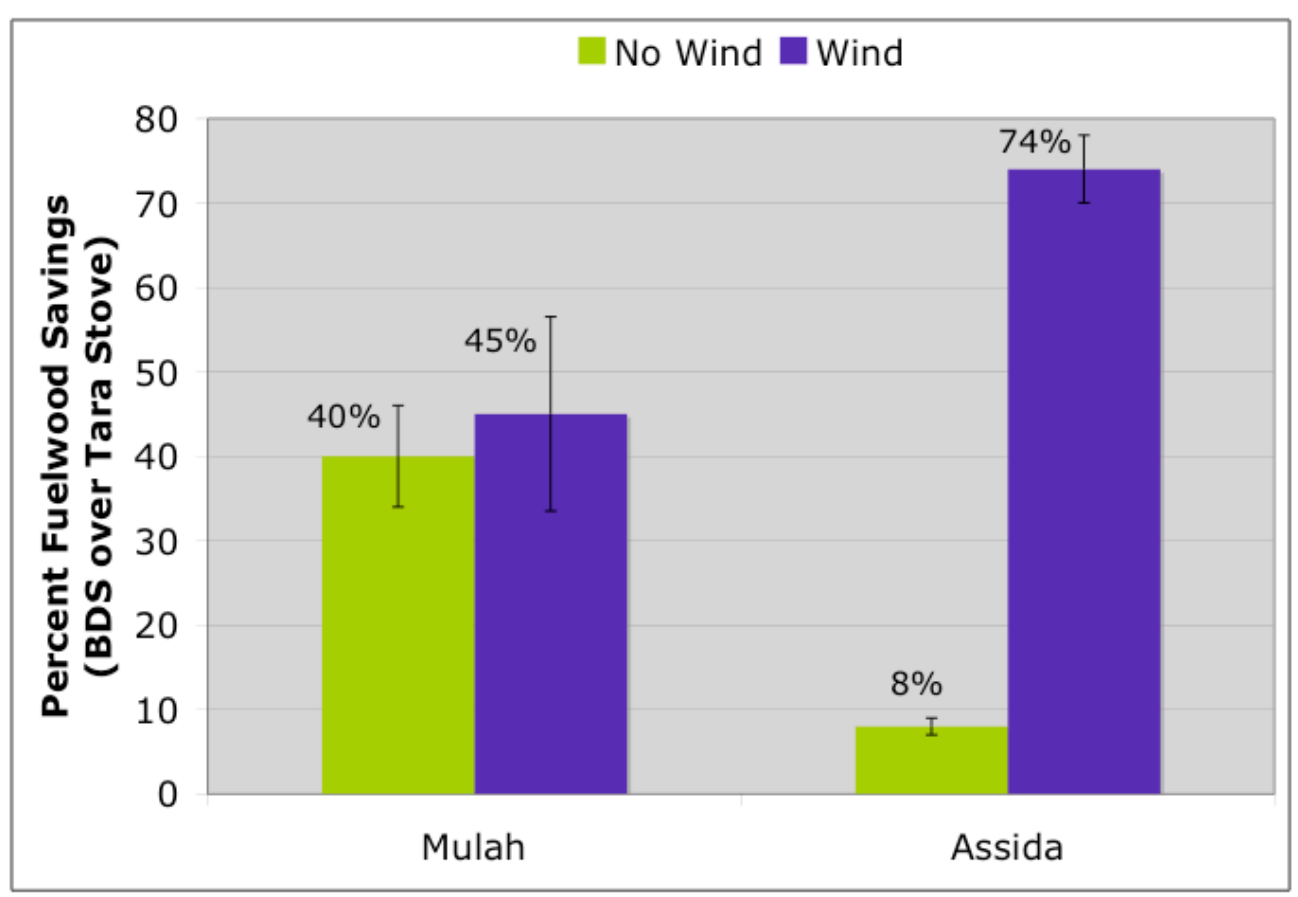

Figure 13: The average fuelwood savings of the BDS over the Tara stove measured for mulah and assida in windy and non-windy conditions. Error bars indicate the measured variation between tests.

\subsubsection{Stability tests}

The stability test was carried out on both the Tara stove and the BDS once. The minimum lateral force required to tip the stove is summarized in Table 4.

Table 4: Stability test results for the Tara stove and the BDS.

\begin{tabular}{|c|c|c|}
\hline Date & \multicolumn{2}{|c|}{ Tipping Force (N) } \\
\hline $5 / 5 / 06$ & Tara Stove & BDS \\
\hline \multirow{2}{*}{} & 22 & $>117$ \\
\cline { 2 - 3 }
\end{tabular}


For the Tara stove, the tipping force is quite small - only $22 \mathrm{~N}$, equivalent to lifting about $2.25 \mathrm{~kg}$. It is not surprising that the IDPs had tipping problems during the November 2005 visit. However, the BDS could not be tipped even when the maximum force measurable on our scale was applied ( $>117 \mathrm{~N}$ or lifting $12 \mathrm{~kg}$ ). In fact, we were able to continue applying force beyond the capacity of the scale and found that it would not tip even with what felt like double the force applied. As we attempted to lean with our entire body weight (far more than the pot would experience during normal cooking), the pot did finally begin to tip.

This test was completed in an area with fairly moist compact dirt. We would like to repeat this test on sandy terrain to get a lower limit of the force (Darfur is neither loose like a beach nor hard and compact like moist dirt).

\subsection{Implications}

The Berkeley Darfur Stove has great potential for improving the environment while simultaneously improving the safety, security, and well being of IDP women currently suffering in Darfur. Details and calculations follow.

\subsubsection{Environmental Implications}

Survey data from Galitsky et al. (2006) showed that $90 \%$ of IDPs currently use a threestone-fire for most or all of their cooking needs. An average IDP household in South Darfur uses about $5 \mathrm{~kg}$ of fuelwood per day and has seven members. Estimates of 2.2 million IDPs imply 280,000 three-stone-fire households using a total of 1.4 million $\mathrm{kg}$ of fuelwood each day, or 510 million $\mathrm{kg}$ of fuelwood annually. With a $72 \%$ savings in fuelwood, an average household in Darfur could save over $1300 \mathrm{~kg}$ in fuelwood annually. If the BDS is successfully adopted by all IDPs, the savings would be over 370 million $\mathrm{kg}$ of fuelwood annually (see detailed calculation below) - a huge dent in the current unsustainable denudation of trees in Darfur. We do note that some of this fuelwood is not harvested from the immediate vicinity of the IDP camps, but brought to the camps by middlemen who sell it for cash - cash that is commonly obtained by the IDP women by selling a part of their meager food rations to other middlemen.

Annual fuelwood savings are estimated at the technical potential with the following equation:

$\begin{aligned} \text { Annual Savings }= & \left(\frac{\text { Current Household Use }}{\text { day }}\right)\left(\frac{365 \text { days }}{\text { year }}\right)(\text { Fuelwood Savings }) \\ & \left(\frac{\text { Number of IDPs }}{\text { IDPs per Household }}\right)(\text { Fraction using three - stone - fire })\end{aligned}$

Plugging numbers into the above equation:

Annual Savings $=\left(\frac{5 \mathrm{~kg}}{\text { day }}\right)\left(\frac{365 \text { days }}{\text { year }}\right)(0.72)\left(\frac{2.2 \text { million }}{7}\right)(0.90)=370$ million kg 
The avoided combustion of 370 million $\mathrm{kg}$ of wood each year will also reduce $\mathrm{CO}_{2}$ emissions and help alleviate global warming. A rough calculation using $0.15 \mathrm{TJ} /$ ton as the net caloric value of wood (IPCC default value for wood) and $109.6 \mathrm{tCO}_{2}$ emitted/TJ (IPCC default for biomass) shows that we have the potential to avoid 6 million tonnes of $\mathrm{CO}_{2}$ emissions per year (see calculation below).

Rough estimate of avoided $\mathrm{CO}_{2}$ emissions at the technical potential:

$$
\text { Avoided } \mathrm{CO}_{2}=\left(\frac{\text { Fuelwood saved }}{\text { year }}\right)(\text { Net Caloric Value })\left(\text { Emitted } \mathrm{CO}_{2}\right)
$$

After plugging in numbers:

$$
\begin{aligned}
& \text { Avoided } \mathrm{CO}_{2} \text { (in tonnes) }=\quad(370 \text { million } \mathrm{kg})\left(\frac{1 \mathrm{t}}{1000 \mathrm{~kg}}\right)\left(\frac{0.15 \mathrm{TJ}}{\mathrm{t}}\right)\left(\frac{109.6 \mathrm{tCO}_{2}}{\mathrm{TJ}}\right) \\
&=6 \text { million } \mathrm{tCO}_{2}
\end{aligned}
$$

We note that "Technical Potential" assumes 100\% saturation (among the $90 \%$ of the IDP households currently using three-stone fires for cooking), and no "takeback" effect. The takeback effect refers to increased use of services (in this case cooking) owing to the availability of a higher efficiency appliance. For example, with more fuel efficient stoves, IDPs would stop missing meals for want of fuel, and thus some increase in fuelwood consumption will result from increased number of meals. Also, those currently selling food to buy fuelwood could sell less, leaving more food to be cooked and hence requiring more fuelwood to cook it with.

\subsubsection{Disposable Income}

Given the 200 SDD ( $\$ 0.80$ October 2007 US) spent daily on fuelwood in South Darfur (Galitsky et al, 2006) by IDP families who buy fuelwood (often by selling food rations), the BDS could save 52,000 SDD (\$222 US) annually per family, leading to a substantial increase in disposable income. This money could be used for better nutrition, clothing, improved shelter, schooling, medical care, and much more. The cost of fuelwood is somewhat higher in North Darfur, but we use the lower number here for a conservative estimate. The same takeback effects may apply as discussed in Section 5.3.1 above.

Some IDPs who currently subsist by selling fuelwood may be adversely affected by the introduction of fuel efficient stoves, through a reduction in income from reduced firewood sales. However, a small number of these people may be incorporated into the stove manufacturing and distribution process, which will take place in the camps and provide extra income to IDPs. Others may find productive employment in the increased economic activity in the camps that will result from a higher disposable income among IDPs using the stove. 


\subsubsection{Safety, Well-Being, and Health}

IDPs who currently walk an average of 25 hours per week to collect fuelwood while risking rape and mutilation (Galitsky et al, 2006) would benefit greatly from a drastic decrease in risk. Reducing the fuelwood collected to one-quarter of the current amount means a reduction of three-quarters in fuelwood collection trips. In addition, the time saved would allow for income generating activities or much needed rest.

There are direct benefits to health from using the BDS as well. The reduction in fuelwood burned, as well as improved combustion as a result of the BDS design, will likely reduce the amount of cooking smoke inhaled by IDP women as they cook (although an emissions study has not yet been done). Cooking smoke is recognized in the environmental literature for having adverse health effects. Also, as indicated in Galitsky et al. (2006), women (primarily in North Darfur) are facing significant health problems associated with burning a type of wood called oudar, a stick whose smoke can produce eye irritation and blindness. The improved efficiency will reduce the volume of oudar burned, resulting in decreased exposure to its harmful effects.

\subsection{The DCT - Recommendations and Lessons Learned}

After completing the first round of BDS testing using the Darfur Cooking Test (DCT), we have discovered a number of best practices and recommendations for future work to make the test more reliable and robust.

1) As stated in section 4.1.1, we recommend investigation into the practice of covering the pot with a lid during the boiling phase of assida making. If regional variations are found, then a comparison study of the fuelwood use under both methods (lid versus no lid) may be warranted.

2) In order to save testing and stove development time, we halved the amount of onions and oil used by IDPs in the making of mulah. A comparison study is needed to characterize the effects of using the full amount of ingredients on the fuelwood usage of the stove. The fuelwood usage is unlikely to scale perfectly linearly since the surface area to volume ratio does not scale linearly as more ingredients are added to the pot.

3) We recommend completing the full stove test for a single stove repeatedly until the standard deviation of fuelwood consumption stabilizes.

4) The anemometer used in our tests was not best suited to the relatively small (4-6 $\mathrm{mph} / 2-3 \mathrm{~m} / \mathrm{s}$ ) winds used in this study. As such, the measured speeds have a relatively large uncertainty that could be reduced through the use of a bettersuited instrument.

5) We did not enforce a designated fan-to-stove distance during wind tests. This may have contributed to a larger than necessary variation in the wind speed. The small size of the fan $(12-i n c h / 30.5 \mathrm{~cm}$ diameter) relative to the distance from the stove (approximately 4 feet $/ 122 \mathrm{~cm}$ ) may have also contributed to further 
variability. Further study on ways to inexpensively produce a more stable and reproducible wind is recommended.

6) More data on the wind conditions in Darfur (average speed and characterization, such as gusty versus constant, etc.) would be useful to ensure that the wind conditions of the test are as realistic as possible.

7) Strict use of the Full Stove Test worksheet (Appendix 2), or a similar worksheet, during each test to prompt the testing personnel to record all relevant data, is highly recommended.

8) We recommend recording the ambient temperature at the time of the test, as this may affect combustion and heat loss rates for an open cooking pot.

\section{Conclusions}

The Berkeley Darfur Stove was designed and fabricated to increase stability during vigorous stirring and increase performance in the presence of wind, both necessary for good stove performance in the specific conditions of IDP camps in Darfur. The Darfur Cooking Test (DCT) protocol was developed to compare the fuelwood savings between any two stoves in the specific environment of Darfur. The test includes a standardized method to test performance in presence of wind as well as in quiescent air, and is based on heating tasks that mimic the cooking tasks of IDPs. The performance of the BDS has been compared to that of the Tara stove using the DCT. The BDS was found to save $40 \%$ and $56 \%$ of the fuelwood required to cook mulah under non-windy and windy conditions respectively, and to save $8 \%$ and $74 \%$ of the fuelwood required to cook assida under non-windy and windy conditions respectively. We estimate that the BDS saves $72 \%$ of the fuelwood required to cook both mulah and assida together on a three-stone fire over the course of one year.

Dissemination of the Berkeley Darfur Stove has the potential to drastically reduce the risk of rape and mutilation of IDP women through avoided fuel collecting trips. It also has the potential to provide significant economic benefit to IDP women via avoided fuelwood costs, or income using freed-up time for productive labor. Lastly, it is expected to reduce exposure to smoke from fuelwood burning.

\section{References}

Galitsky, C., Gadgil, A., Jacobs, M., Lee, Y., 2006, "Fuel efficient stoves for Darfur IDP camps: Report of field trip to North and South Darfur, Nov. 16-Dec. 17, 2005." Lawrence Berkeley National Laboratory Report LBNL-59540.

Balis, R., Ogle, D., Still, D., Smith, K.R., and R. Edwards, 2004, "The Water Boiling Test (WBT), Version 1.5", Household Energy and Health Program, Shell Foundation, http://ehs.sph.berkeley.edu/hem/page. asp?id=42 


\section{Acknowledgements}

This work was partly supported by the Director, Office of Science, of the U.S. Department of Energy under Contract No. DE-AC02-05CH11231. We are grateful to several individuals for their support (in cash and in kind), through gifts via LBNL or UC Berkeley. We thank the Energy and Resources Group and College of Engineering at UCBerkeley for their support during 2006 to the course ER291 Design for Sustainable Communities, which made this project possible.

The authors wish to thank a number of individuals who have provided valuable support for this project. The first four authors thank, first and foremost, Ashok Gadgil (co-author) for many hours of valuable advice as our mentor and for developing and teaching the course Design for Sustainable Communities. We thank Ashley Murray and Fermin Reygadas, the GSIs for the course, along with the Berkeley student chapter of Engineers for a Sustainable World who had a pivotal role in creating and offering this great course. We also thank all of the fellow students in the course from Spring 2006 for their valuable guidance and feedback.

We would like to thank Jonathan Slack and Howdy Goudy, both of LBNL, for their extensive help with fabrication and design of the BDS, as well as use of their workshop. We thank Christie Galitsky for her valuable advice and discussions about Darfur. We thank Austin Hedeman for offering his electric range and help. We thank the neighbours and roommates of G.T. Kisch for putting up with (very early) stove tests in his backyard. We thank the Gadgil family for lending us equipment and support to keep us out of the rain.

Finally, we would like to thank the Darfur Stoves Project for financial assistance, the use of stove testing equipment, and the original Tara stove that we modified to create the BDS prototype.

\section{Afterward}

The Berkeley Darfur Stove was further improved substantially during the summer and fall of 2006 by Engineers Without Borders - San Francisco Professional Chapter. For more updates and current progress, see www.darfustoves.org. 


\section{Appendix 1: Darfur Cooking Test Protocol}

Darfur Stoves Project - July 14, 2006

The fuelwood consumed in cooking depends on five factors (in addition to ambient wind conditions):

1. The cook (her/his ability and skill in tending the fire in the stove makes a big difference)

2. The fuelwood (moisture content, density, composition (bark, surface, core), diameter, wood species - all these make a difference. So, stay with some standard stock if at all possible)

3. The stove (influences combustion and heat transfer efficiencies)

4. The pot (the way this fits on to the stove influence heat transfer, and also combustion efficiency)

5. The type of food being cooked (frying onions for mulah makes different demands than making assida or baking flat bread).

It is important that the person tending the fire, "the fire-tender" is not a novice. Otherwise, the results will change as the novice gains experience and becomes skilled. We recommend that the novices perform many "throw-away" tests to gain experience in tending the fire in the stove. We too had to do that.

Many observers have noted that people who routinely cook (e.g., IDP women from refugee camps) are not automatic experts in tending fires in improved stoves just because they tended fires in other cooking situations. However, they can be trained very quickly if given guidance.

\section{Definition of One Full Stove Test}

A new stove (call this STOVE A) is tested by comparison to another stove (call this STOVE B). It must be tested for making both mulah and assida (or rather a proxy version of each with the same thermodynamic properties), in both windy and non-windy conditions. Thus one full stove test consists of eight sub-tests:

ONE FULL STOVE TEST IS:

1A. Mulah test using Stove A and no wind.

1B. Mulah test using Stove B and no wind.

2A. Mulah test using Stove A with wind.

2B. Mulah test using Stove B with wind.

3A. Assida test using Stove A and no wind.

3B. Assida test using Stove B and no wind.

4A. Assida test using Stove A with wind.

4B. Assida test using Stove B with wind. 
For tests 1A, 1B, 2A, and 2B, use the Mulah Test Protocol (Section I) with and without wind as appropriate. For tests 3A, 3B, 4A, and 4B, use the Assida Test Protocol (Section II) with and without wind as appropriate.

In addition, to take care of statistical fluctuation, the full stove test above should be repeated three times (over three days) for each set of stoves you want to test. One Full Stove Test Worksheet (Appendix 2) represents one Full Stove Test. To complete the testing of a set of stoves, you will fill out 3 Full Stove Test Worksheets.

Safety Note: To ensure safety, be sure to keep a fire extinguisher within reach and clear an area around the stove of about 2 square meters

\section{Required Equipment}

Equipment List

Non-Consumable:

- Stove A

- Stove B

- Small Tungutungu pot*

- Large Tungutungu pot**

- Weighing Scale

- Thermocouple (Digital Thermometer)

- Anemometer

\section{Description}

One of the stoves you wish to compare. Generally the one expected to be less efficient.

The other stove you wish to compare. Generally the one expected to be more efficient.

Round-bottomed pot (19 cm diameter) used in Darfur to cook mulah.

Round-bottomed pot (23 cm diameter) used in Darfur to cook assida.

Digital battery powered scale with precision of 1 gram, max $1 \mathrm{~kg}$.

Digital thermocouple capable of measuring temperatures between $20-130^{\circ} \mathrm{C}$.

A cup anemometer (to measure wind from all directions) that can be placed between the fan and stove and can measure wind speeds between 0-10 mph $(0-5 \mathrm{~m} / \mathrm{s})$. 


\section{Equipment List}

- Table Fan (WIND TEST ONLY) (possibly extension cord and electricity access)

- 2 Medium/Large Mixing Bowls

- Wooden spoon

- 2 Pairs of Heat Resistant Gloves

- Small Measuring cup (500 mL)*

- $\quad$ Large Measuring Cup (1 - 2L)

- Watch or Stopwatch

- 15 Minute Timer**

- Flat metal pan (optional)

- All-purpose towel (optional)

- $\quad$ Fire extinguisher (optional)

- An old shirt or smock (optional)

\section{Description}

A simple table fan with a diameter $>12$ inches $/ 30 \mathrm{~cm}$. Note: if it plugs in, you will also need an extension cord and electricity access.

To hold the wood on the scale. One bowl is for unburned wood, and the other is for coals after the test.

To stir the proxy-mulah or proxy-assida during tests. Wrap the thermocouple leads around the spoon and fasten with a clip.

To move the hot stove and lift the hot pots from the stove to put out the fire.

To measure and weigh cut onions.

To measure $2.5 \mathrm{~L}$ water for assida test. Also used to hold water to douse the fire after a test.

To record total cooking time and time to boil.

To measure post-boil time in assida test.

A piece of sheet-metal to put under the stove to collect ash.

For clean-up and use as a knee-pad during the test.

Appropriate for wood fires.

You will get your clothes dirty! 


\section{Consumable:}

- Chopped White Onion*

- 235g (420 mL) per mulah test

- $940 \mathrm{~g}(1680 \mathrm{~mL})$ per full stove test

- Corn oil*

- $200 \mathrm{~mL}$ per mulah test

$-800 \mathrm{~mL}$ per full stove test

- Water**

- $2500 \mathrm{~mL}$ per assida test

- 10L per full stove test

- Wood

(Amount needed depends on the stove tested; windy conditions require more wood)

$\sim 400$ - 500g per mulah test

$\sim 600$ - 2000g per assida test

$\sim 10 \mathrm{~kg}$ per full stove test

- Newspaper and twigs

- Hatchet

- Matches

- Small bucket or cup of water $\sim 200 \mathrm{~mL}$ per test

$\sim 1600 \mathrm{~mL}$ per full stove test

- One fresh copy of the FULL STOVE TEST WORKSHEET

*Needed for mulah test only.

**Needed for assida test only.
Freshly chopped into small pieces $(\sim 1 \mathrm{~cm} \mathrm{x}$ $2 \mathrm{~cm}$, 1 in $\mathrm{x} 0.5$ in each). Note: $235 \mathrm{~g}$ is about one small onion. To ensure constant moisture content in the onions, buy all of the onions for a full stove test at the same time and chop them within a few hours of doing the test. Cover chopped onions to avoid drying them out.

Standard vegetable oil is fine too.

If bringing water to the site, don't forget to bring extra to douse the fire and to clean the pot after a mulah test.

Wood should all be of the same type (soft vs hard) and of the same or similar moisture content for all tests. Cut wood into pieces of $\sim 3 \mathrm{~cm}$ (1.2 in) diameter and $15-20 \mathrm{~cm}$ (6 8 in) length.

To start the fire and for kindling. Weigh the kindling with the wood (but not the newspaper).

For splitting and cutting wood.

To start the fire. A firestarter also works.

To douse the fire after each test (you can use the large measuring cup).

See Appendix 2 


\section{Mulah Test Protocol - with and without wind}

Two persons are needed to conduct the test. The person managing the fire is the "fire tender", and the other stirring the onions continuously at a set speed is the "stirrer". A third person to record that data is helpful, but in a pinch, the fire-tender could also write down data between paying attention to the fire.

\section{SETUP PHASE}

If you have not chopped the onions yet, do so now (see Equipment List for amounts, size, etc).

(Steps 1-7 can be done in any order)

1. Open your full stove test worksheet to the appropriate page for this test and fill in what you can.

2. Put the $235 \mathrm{~g}$ ( $420 \mathrm{~mL}$ or 1.75 cups) of chopped onion and the $200 \mathrm{~mL}$ corn oil together in the small Tungutungus pot (we called it the mulah pot). Record the exact amounts you used on your worksheet.

* Note about the scale (refers to Salter Model): always make sure that the scale is set to grams (a small $g$ should appear to the right hand side of the measurement). To change the units, keep pressing the $\mathrm{kg} / \mathrm{lb}$ button until the $g$ appears.

3. Place the stove to be tested on the flat metal pan on flat ground. Leave room for the fire-tender to feed wood into the stove and a stirrer to sit to one side and constantly stir. If this is a wind test, note that the smoke will be directed by the fan - try to avoid a situation where the smoke is blowing into someone's eyes.

4. Set up the anemometer to measure the wind speed (do this even if you are not using the fan, so that you get the background wind speed). Prop it up on some wood so that the cups are level with the spot where the windshield meets the stove. Make sure the stirrer will not be blocking the wind as it hits the anemometer. Re: Maxim BTC Hand Held Anemometer: it is hard to read wind speeds below $5 \mathrm{mph}$, but you can distinguish between 0 (when the cups are not moving) and 1-4 mph (which you can estimate when the cups are moving and the reading is not yet $5 \mathrm{mph}$ ). Read the top scale, NOT the red scale.

*If there is too much ambient wind (more than $2 \mathrm{mph} / 1 \mathrm{~m} / \mathrm{s}$ ), move the test to a more sheltered location. 
4b. (WIND TEST ONLY): If this is a test with wind, set up a table fan about half a meter from the center of the stove with the anemometer between the stove and fan (make sure the fan and anemometer will not be blocked by the stirrer or fire tender). Adjust the fan settings (we used low) and distance between the fan and the stove until the anemometer reads about 4-6 mph (2- $3 \mathrm{~m} / \mathrm{s})$. Turn off the fan until after the fire is started.

5. Wrap the thermocouple probe around the handle of the wooden spoon and use the clip (or tape) to attach the probe tip about $1 \mathrm{~cm}$ from the bottom of the spoon. We tried and used several methods for keeping the tip in place; the best configuration had a clip securing the probe to the spoon handle and another clip holding the probe tip in place $1 \mathrm{~cm}$ from the bottom of the spoon (note that the tape alone will loosen as the oil heats up). Place the spoon with probe attached into the mulah pot. The probe should read the current temperature of the oil (note that the DT12 model thermocouple reads only Fahrenheit - the conversion is $\mathrm{F}=9 / 5^{*} \mathrm{C}+32$, where $\mathrm{F}$ is the Fahrenheit temperature and $\mathrm{C}$ is the Celsius temperature).

If the initial temperature of the onions is very different from the initial temperature of a previous test you are comparing to (more than 5 degrees), try cooling the pot on the outside with cold water.

*Note (refers to Fluke Thermocouple): The fluke meter (with a yellow cover) can read two temperature probes at once. We only need one, so we will just use the T1 settings. Plug in the probe to the left hand slot (labeled T1). Press the T1 button to see the reading from this probe. Make sure that it is reading Celsius (check for a $C$ on the display). To change between Celsius and Fahrenheit, press the F/C button.

6. Measure out the wood you will use with the scale and the mixing bowl. **Make sure that you press ZERO on the scale with the empty bowl before putting any wood on it ** - check the 'zeroed scale' box on your worksheet to verify that you zeroed the scale and that the weight of your wood makes sense (it is not too high or too low given your experience). Make sure to include some small twigs for kindling and starting the fire. (Note: We also use newspaper, but did not include it in the weight because it is burned up by the time the pot is placed on the stove). RECORD THE INITIAL WEIGHT OF THE WOOD.

\section{ONCE YOU HAVE WEIGHED THE WOOD, PUT ALL OTHER WOOD AWAY AND OUT OF REACH!}

*If you need more wood after a test has started, carefully weigh the additional wood you wish to add and add that amount to the initial weight under INITIAL WOOD WEIGHT. Make a note that you did this in the notes section of your worksheet.

7. Fill a cup with water $(\sim 200 \mathrm{~mL})$ and put in easy reach (to douse the fire at the end). 


\section{TESTING PHASE}

8. Prepare the stove by putting in some wads of newspaper with twigs on top. Place some larger pieces of wood on top of the twigs (we found a teepee formation worked best). Light the paper with a match or lighter. Wait until the large pieces of wood have caught fire.

8b. (WIND TEST ONLY) Turn the fan back on (recall that you turned it off to light the fire).

9. Once the fire is going, put the small pot with the wooden spoon and probe in it on the stove. RECORD THE START TIME AND INITIAL TEMPERTURE. Also RECORD THE AVERAGE WIND SPEED (watch the dial for 10-20 seconds and estimate the average).

10. Have one team member sit and constantly stir the oil/onion mixture with the wooden spoon at a rate of about 1 time around per second. Every minute or so, use the spoon to push the onions back into the oil (they will stick to the sides).

11. Have another member tend the fire. Add pieces of wood one by one, just enough to keep the fire going (do not overstuff the fire). However, use enough wood to make sure the fire doesn't go out. This is the most difficult part. DO NOT give in to the temptation to overstuff the fire in order to speed up the test.

12. Continue this until the thermometer reads $120^{\circ} \mathrm{C}\left(244^{\circ} \mathrm{F}\right)$. The onions are now 'cooked' and should be starting to turn brown (it should take about 20-30 min). At this point, take the pot off of the fire (using gloves) and douse the fire with water just enough to stop the flames; do not soak it (note: you can also tip the stove and shake all the burning wood pieces onto the metal pan and douse them there). RECORD THE END TIME

13. Pick up the stove (using gloves) and shake out all of the wet coals onto the metal pan.

14. Weigh and RECORD THE WEIGHT OF THE UNUSED WOOD (this is the leftover wood that you weighed initially, but did not put into the stove).

REMEMBER TO ZERO THE SCALE!

15. Using gloves, place all of the wet coals from the stove into the mixing bowl, and put the bowl onto the scale. Weigh and RECORD THE WEIGHT OF THE COALS. REMEMBER TO ZERO THE SCALE! After weighing the coals, soak them well with water before throwing them away.

16. Follow the directions on the full stove test worksheet to calculate the total wood burned. 


\section{COOL DOWN PHASE}

17. Cool down the Tungutungus pot and stove with cold water if you plan to do another test immediately. This is very important so that all tests start with the same temperature pot and stove. Alternating between stoves gives one stove a chance to cool off while the other is being tested.

\section{END OF MULAH TEST}

\section{CLEAN-UP TIPS}

- You may want some soap to clean up the oil from the small Tungutungus pot.

- Put the hot onions in a pan to cool. You can eat them or throw them away.

- After weighing, soak the coals again before throwing them away (or save them for charcoal).

- Hot water and soap works for getting the soot off of you hands and face (cold water alone is not enough).

\section{WHEN TO STOP A TEST AND REPEAT (IT IS VERY IMPORTANT TO FOLLOW THIS)}

- If you find an extra piece of wood after the fire has started and you are not sure if it was weighed - RESTART THE TEST. This time, put all other wood away after weighing it.

- If the fire goes out for more that 3 minutes during a test (or the temperature drops by more than $10^{\circ} \mathrm{C}$ or $20^{\circ} \mathrm{F}$ ) - RESTART THE TEST.

- If you forget or miss the stop condition by more than $5^{\circ} \mathrm{C}$ or $10^{\circ} \mathrm{F}$ (for mulah) or more than 3 min (for assida) - RESTART THE TEST.

- If the wind increases by $5 \mathrm{mph}(2 \mathrm{~m} / \mathrm{s})$ for more than one-quarter of the total time the fire is lit - RESTART THE TEST. Note: small gusts of wind are ok

- Use your judgment - to have a useful result, the conditions of the test for Stove A need to be as similar as possible to the conditions for Stove B. If you feel that the conditions may not be as similar as you are you reasonably able to make them RESTART THE TEST.

** Whenever you restart a test, throw all the data away (just for that page of the worksheet) and start that page over from the beginning - i.e. re-weigh the wood and use fresh onions, oil, water etc. ${ }^{* *}$ 


\section{Assida Test Protocol - with and without wind}

\section{SETUP PHASE}

(Steps 1-7 can be done in any order)

1. Open your full stove test worksheet to the appropriate page and fill in what you can.

2. Measure $2500 \mathrm{~mL}$ of water using the large measuring cup and pour it in the large Tungutungus pot.

Repeat steps 3-7 of the Mulah Test Protocol

\section{TESTING PHASE}

Repeat step $\mathbf{8}$ of the Mulah Test Protocol

9. Once the fire is going, put the large Tungutungus pot with the wooden spoon and probe in it on the stove with the lid off ${ }^{1}$. RECORD THE START TIME AND INITIAL TEMPERTURE.

10. Have one team member tend the fire. Add pieces of wood one by one, just enough to keep the fire going (do not overstuff the fire). However, use enough wood to make sure the fire doesn't go out. This is the most difficult part. DO NOT give in to the temptation to overstuff the fire in order to speed up the test.

11. Watch for the water to just begin boiling (when the temperature is near $100^{\circ} \mathrm{C}$ or $212^{\circ} \mathrm{F}$ ). This can take $10-40$ minutes. RECORD THE TIME WHEN BOILING BEGINS.

12. Remove the lid from the pot (if on). Set your timer (or watch) for 15 minutes. Try to keep the water just barely boiling the entire time (make sure the temperature does not go below the boiling temperature by more than $10^{\circ} \mathrm{C}$, or about $20^{\circ} \mathrm{F}$ ).

13. Have one team member constantly stir the water during the 15 minutes. Use the wooden spoon and stir at a rate of about 1 time around per second.

14. After 15 minutes, take the pot off of the fire (using gloves) and douse the fire with water - just enough to stop the flames; do not soak it (note: you can also shake the entire fire onto the metal pan and douse it there).

Repeat steps 13-17 of the Mulah Test Protocol.

See Mulah Test Protocol for clean-up tips and when to stop a test and repeat.

\section{END OF ASSIDA TEST}

\footnotetext{
${ }^{1}$ As of this writing, we have received contradictory information on the use of a lid during the boiling phase of assida. In 2005, no lid was used during side-by-side tests. However, in 2006, we were told by NGO workers that lids are always used. We recommend more research into the use of a lid in Darfur, and at the very least, diligent recording of whether or not a lid is used in any given test.
} 
Appendix 2

\section{FULL STOVE TEST WORKSHEET \\ Darfur Cooking Test}

Modified Oct 3, 2007

Name of Stove A:

Name of Stove B:

Date:

Location:

Full Stove Test:

of 3

Testers: 


\section{A. Mulah TEST using STOVE A - NO WIND.}

Date:

Fire-Tender:

Stirrer:

Onions used (grams):

Oil used (mL):

DATA:

Before lighting the fire, fill out the following:

a. INITIAL WOOD WEIGHT (grams): zeroed scale

b. START TIME:

c. INITIAL TEMPERATURE: (be sure to put ${ }^{\circ} \mathrm{C}$ or ${ }^{\circ} \mathrm{F}$ )

After lighting the fire, fill out the following:

d. AVERAGE WIND SPEED (mph):

After reaching $120^{\circ} \mathrm{C}\left(244^{\circ} \mathrm{F}\right)$, fill out the following:

e. END TIME: COOKING TIME (minutes):

f. UNUSED WOOD WEIGHT (grams): zeroed scale

g. LEFTOVER COALS WEIGHT (grams): zeroed scale

h. Sum of unburned wood $(\operatorname{add} f$ to $g)$ :

i. TOTAL WOOD BURNED (subtract $h$ from $a$ ):

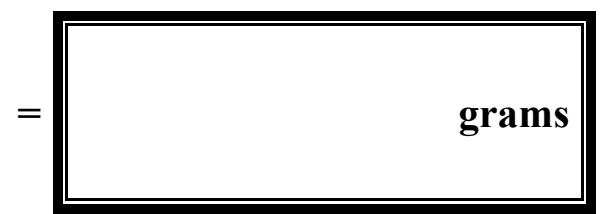

j. Notes (record here and on the back anything that was different from the normal protocol, or any small mistakes that were made and corrected): 


\section{B. Mulah TEST using STOVE B - NO WIND.}

*Remember to use the SAME fire-tender and stirrer as test $1 A^{*}$

Date:

Fire-Tender:

Stirrer:

Onions used (grams):

Oil used (mL):

DATA:

Before lighting the fire, fill out the following:

k. INITIAL WOOD WEIGHT (grams):

zeroed scale

1. START TIME:

m. INITIAL TEMPERATURE: (be sure to put ${ }^{\circ} \mathrm{C}$ or ${ }^{\circ} \mathrm{F}$ )

After lighting the fire, fill out the following:

n. AVERAGE WIND SPEED (mph):

After reaching $120^{\circ} \mathrm{C}\left(244^{\circ} \mathrm{F}\right)$, fill out the following:

o. END TIME: COOKING TIME (minutes):

p. UNUSED WOOD WEIGHT (grams): zeroed scale

q. LEFTOVER COALS WEIGHT (grams): zeroed scale

r. Sum of unburned wood (add $p$ to $q)$ :

s. TOTAL WOOD BURNED (subtract $r$ from $k$ ):

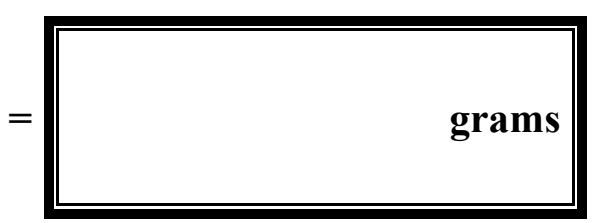

t. Notes (record here and on the back anything that was different from the normal protocol, or any small mistakes that were made and corrected): 


\section{1: Fuelwood Savings of Stove B over Stove A for mulah with no wind}

Fuelwood Savings of B over A: $\quad F S_{A B}=\frac{W_{A}-W_{B}}{W_{A}} * 100$

where $\mathrm{W}_{\mathrm{A}}$ is the weight of fuelwood used by Stove $\mathrm{A}$ and $\mathrm{W}_{\mathrm{B}}$ is the weight of fuelwood used by Stove B.

u. Calculate the difference in fuelwood used by the two stoves (subtract $s$ from $i$ ):

$=$ grams

v. Divide your answer by the fuelwood used in STOVE A ( $u$ divided by $i$ : record to two decimal places):

$=$ grams

w. Multiply by 100 to get the percent fuelwood savings for mulah with no wind ( $v$ times 100):

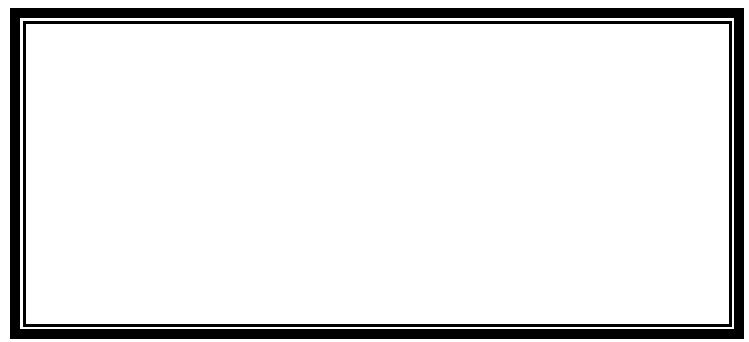

MULAH WITH NO WIND 


\section{A. Mulah TEST using STOVE A - WITH WIND.}

Date:

Fire-Tender:

Stirrer:

Onions used (grams):

Oil used (mL):

DATA:

Before lighting the fire, fill out the following:

a. INITIAL WOOD WEIGHT (grams): zeroed scale

b. START TIME:

c. INITIAL TEMPERATURE: (be sure to put ${ }^{\circ} \mathrm{C}$ or ${ }^{\circ} \mathrm{F}$ )

After lighting the fire, fill out the following:

d. AVERAGE WIND SPEED (mph):

After reaching $120^{\circ} \mathrm{C}\left(244^{\circ} \mathrm{F}\right)$, fill out the following:

e. END TIME: COOKING TIME (minutes):

f. UNUSED WOOD WEIGHT (grams): zeroed scale

g. LEFTOVER COALS WEIGHT (grams): zeroed scale

h. Sum of unburned wood $(\operatorname{add} f$ to $g)$ :

i. TOTAL WOOD BURNED (subtract $h$ from $a$ ):

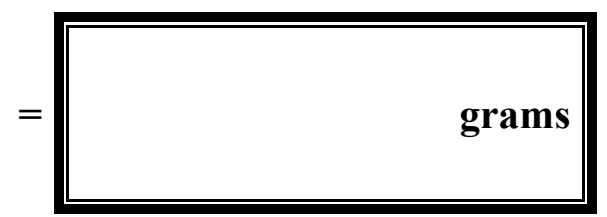

j. Notes (record here and on the back anything that was different from the normal protocol, or any small mistakes that were made and corrected): 


\section{B. Mulah TEST using STOVE B - WITH WIND.}

*Remember to use the $S A M E$ fire-tender and stirrer as test $2 A *$

Date:

Fire-Tender:

Stirrer:

Onions used (grams):

Oil used (mL):

DATA:

Before lighting the fire, fill out the following:

k. INITIAL WOOD WEIGHT (grams): zeroed scale

1. START TIME:

m. INITIAL TEMPERATURE: (be sure to put ${ }^{\circ} \mathrm{C}$ or ${ }^{\circ} \mathrm{F}$ )

After lighting the fire, fill out the following:

n. AVERAGE WIND SPEED (mph):

After reaching $120^{\circ} \mathrm{C}\left(244^{\circ} \mathrm{F}\right)$, fill out the following:

o. END TIME: COOKING TIME (minutes):

p. UNUSED WOOD WEIGHT (grams): zeroed scale

q. LEFTOVER COALS WEIGHT (grams): zeroed scale

r. Sum of unburned wood (add $p$ to $q)$ :

s. TOTAL WOOD BURNED (subtract $r$ from $k$ ):

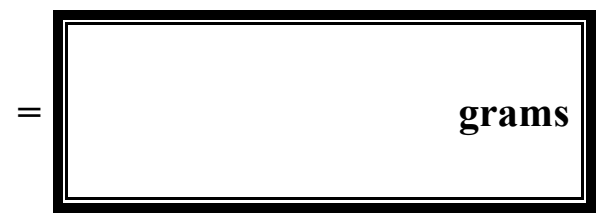

t. Notes (record here and on the back anything that was different from the normal protocol, or any small mistakes that were made and corrected): 


\section{2: Fuelwood Savings of Stove B over Stove A for mulah with wind}

Fuelwood Savings of B over A: $\quad F S_{A B}=\frac{W_{A}-W_{B}}{W_{A}} * 100$

where $\mathrm{W}_{\mathrm{A}}$ is the weight of fuelwood used by Stove $\mathrm{A}$ and $\mathrm{W}_{\mathrm{B}}$ is the weight of fuelwood used by Stove B.

u. Calculate the difference in fuelwood used by the two stoves (subtract $s$ from $i$ ):

$=$ grams

v. Divide your answer by the fuelwood used in STOVE A ( $u$ divided by $i$ : record to two decimal places):

$=$ grams

w. Multiply by 100 to get the percent fuelwood savings for mulah with wind ( $v$ times 100):

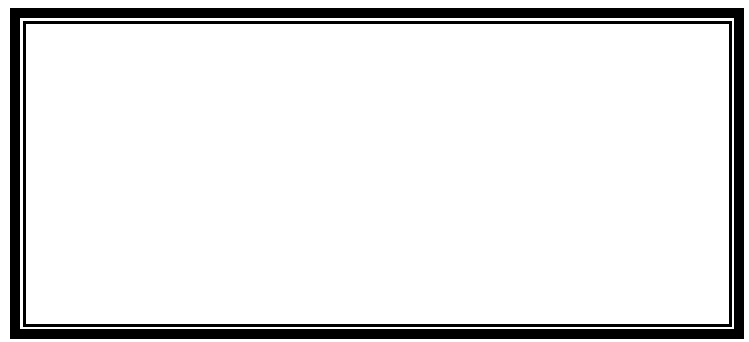

MULAH WITH WIND 


\section{A. ASSIDA TEST using STOVE A - NO WIND.}

Date:

Fire-Tender:

Stirrer:

Water used $(\mathrm{mL})$ :

DATA:

Before lighting the fire, fill out the following:

a. INITIAL WOOD WEIGHT (grams): zeroed scale

b. START TIME:

c. INITIAL TEMPERATURE: (be sure to put ${ }^{\circ} \mathrm{C}$ or ${ }^{\circ} \mathrm{F}$ )

After lighting the fire, fill out the following:

d. AVERAGE WIND SPEED (mph):

After reaching $120^{\circ} \mathrm{C}\left(244^{\circ} \mathrm{F}\right)$, fill out the following:

e. TIME BOIL STARTS: TIME TO BOIL (minutes):

f. UNUSED WOOD WEIGHT (grams): zeroed scale

g. LEFTOVER COALS WEIGHT (grams): zeroed scale

h. Sum of unburned wood (add $f$ to $g$ ):

i. TOTAL WOOD BURNED (subtract $h$ from $a$ ):

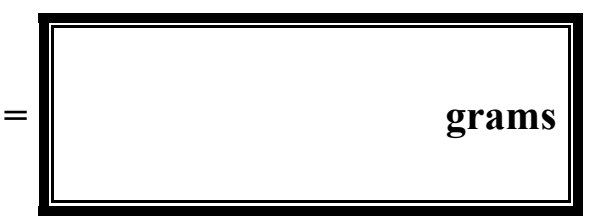

j. Weight (or Vol) of remaining water $(\mathrm{g} / \mathrm{mL})$ :

k. Notes (record here and on the back anything that was different from the normal protocol, or any small mistakes that were made and corrected): 


\section{B. ASSIDA TEST using STOVE B - NO WIND.}

Date:

Fire-Tender:

Stirrer:

Water used $(\mathrm{mL})$ :

DATA:

Before lighting the fire, fill out the following:

1. INITIAL WOOD WEIGHT (grams): zeroed scale

m. START TIME:

n. INITIAL TEMPERATURE: (be sure to put ${ }^{\circ} \mathrm{C}$ or ${ }^{\circ} \mathrm{F}$ )

After lighting the fire, fill out the following:

o. AVERAGE WIND SPEED (mph):

After reaching $120^{\circ} \mathrm{C}\left(244^{\circ} \mathrm{F}\right)$, fill out the following:

p. TIME BOIL STARTS: TIME TO BOIL (minutes):

q. UNUSED WOOD WEIGHT (grams): zeroed scale

r. LEFTOVER COALS WEIGHT (grams): zeroed scale

s. Sum of unburned wood (add $q$ to $r$ ):

t. TOTAL WOOD BURNED (subtract $s$ from $l$ ):

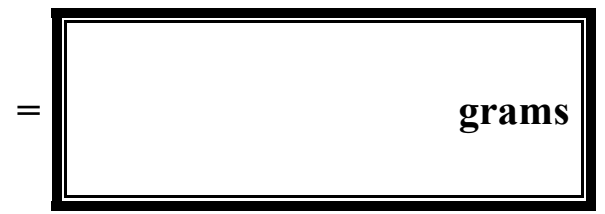

u. Weight (or Vol) of remaining water $(\mathrm{g} / \mathrm{mL})$ :

v. Notes (record here and on the back anything that was different from the normal protocol, or any small mistakes that were made and corrected): 


\section{3: Fuelwood Savings of Stove B over Stove A for assida with no wind}

Fuelwood Savings of B over A: $\quad F S_{A B}=\frac{W_{A}-W_{B}}{W_{A}} * 100$

where $\mathrm{W}_{\mathrm{A}}$ is the weight of fuelwood used by Stove $\mathrm{A}$ and $\mathrm{W}_{\mathrm{B}}$ is the weight of fuelwood used by Stove B.

x. Calculate the difference in fuelwood used by the two stoves (subtract $t$ from $i$ ):

$=$ grams

y. Divide your answer by the fuelwood used in STOVE A ( $x$ divided by $i$ : record to two decimal places):

$=$ grams

z. Multiply by 100 to get the percent fuelwood savings for assida with no wind $(y$ times 100):

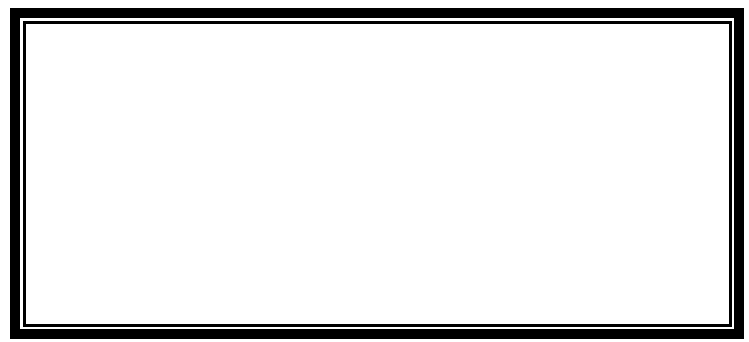

ASSIDA WITH NO WIND 


\section{A. ASSIDA TEST using STOVE A - WITH WIND.}

Date:

Fire-Tender:

Stirrer:

Water used $(\mathrm{mL})$ :

DATA:

Before lighting the fire, fill out the following:

a. INITIAL WOOD WEIGHT (grams): zeroed scale

b. START TIME:

c. INITIAL TEMPERATURE: (be sure to put ${ }^{\circ} \mathrm{C}$ or ${ }^{\circ} \mathrm{F}$ )

After lighting the fire, fill out the following:

d. AVERAGE WIND SPEED (mph):

After reaching $120^{\circ} \mathrm{C}\left(244^{\circ} \mathrm{F}\right)$, fill out the following:

e. TIME BOIL STARTS: TIME TO BOIL (minutes):

f. UNUSED WOOD WEIGHT (grams): zeroed scale

g. LEFTOVER COALS WEIGHT (grams): zeroed scale

h. Sum of unburned wood (add $f$ to $g$ ):

i. TOTAL WOOD BURNED (subtract $h$ from $a$ ):

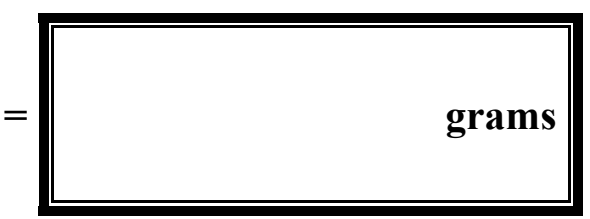

j. Weight (or Vol) of remaining water $(\mathrm{g} / \mathrm{mL})$ :

k. Notes (record here and on the back anything that was different from the normal protocol, or any small mistakes that were made and corrected): 


\section{B. ASSIDA TEST using STOVE B - WITH WIND.}

Date:

Fire-Tender:

Stirrer:

Water used $(\mathrm{mL})$ :

DATA:

Before lighting the fire, fill out the following:

1. INITIAL WOOD WEIGHT (grams): zeroed scale

m. START TIME:

n. INITIAL TEMPERATURE: (be sure to put ${ }^{\circ} \mathrm{C}$ or ${ }^{\circ} \mathrm{F}$ )

After lighting the fire, fill out the following:

o. AVERAGE WIND SPEED (mph):

After reaching $120^{\circ} \mathrm{C}\left(244^{\circ} \mathrm{F}\right)$, fill out the following:

p. TIME BOIL STARTS: TIME TO BOIL (minutes):

q. UNUSED WOOD WEIGHT (grams): zeroed scale

r. LEFTOVER COALS WEIGHT (grams): zeroed scale

s. Sum of unburned wood (add $q$ to $r$ ):

t. TOTAL WOOD BURNED (subtract $s$ from $l$ ):

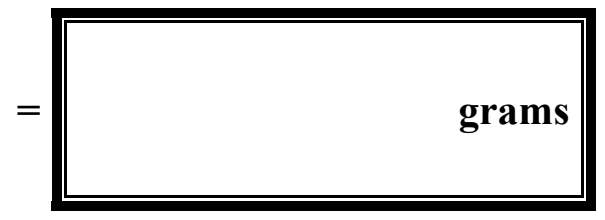

u. Weight (or Vol) of remaining water $(\mathrm{g} / \mathrm{mL})$ :

v. Notes (record here and on the back anything that was different from the normal protocol, or any small mistakes that were made and corrected): 


\section{4: Fuelwood Savings of Stove B over Stove A for assida with wind}

Fuelwood Savings of B over A: $\quad F S_{A B}=\frac{W_{A}-W_{B}}{W_{A}} * 100$

where $\mathrm{W}_{\mathrm{A}}$ is the weight of fuelwood used by Stove $\mathrm{A}$ and $\mathrm{W}_{\mathrm{B}}$ is the weight of fuelwood used by Stove B.

w. Calculate the difference in fuelwood used by the two stoves (subtract $t$ from $i$ ):

$=$ grams

$\mathrm{x}$. Divide your answer by the fuelwood used in STOVE A ( $x$ divided by $i$ : record to two decimal places):

$=$ grams

y. Multiply by 100 to get the percent fuelwood savings for assida with wind ( $y$ times 100):

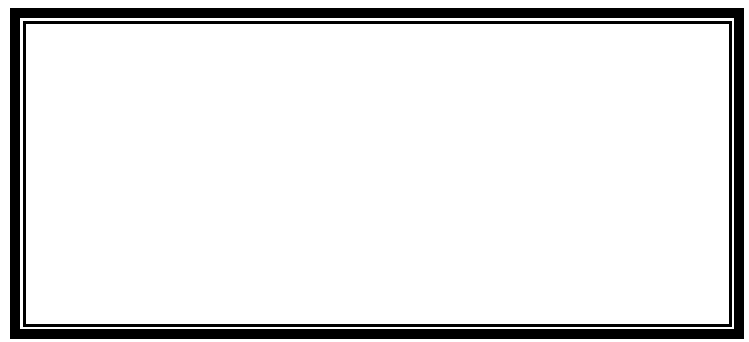

ASSIDA WITH WIND 